\title{
Article \\ Catalytic Behavior of Iron-Containing Cubic Spinel in the Hydrolysis and Hydrothermolysis of Ammonia Borane
}

\author{
Oksana V. Komova *(D), Valentina I. Simagina, Alena A. Pochtar (D, Olga A. Bulavchenko, Arcady V. Ishchenko, \\ Galina V. Odegova, Anna M. Gorlova (D, Anna M. Ozerova (D, Inna L. Lipatnikova, Elena S. Tayban, \\ Svetlana A. Mukha and Olga V. Netskina
}

check for updates

Citation: Komova, O.V.; Simagina, V.I.; Pochtar, A.A.; Bulavchenko, O.A.; Ishchenko, A.V.; Odegova, G.V.; Gorlova, A.M.; Ozerova, A.M.; Lipatnikova, I.L.; Tayban, E.S.; et al. Catalytic Behavior of Iron-Containing Cubic Spinel in the Hydrolysis and Hydrothermolysis of Ammonia Borane. Materials 2021, 14, 5422. https://doi.org/10.3390/ma14185422

Academic Editor: Benjamín Solsona

Received: 27 August 2021

Accepted: 16 September 2021

Published: 19 September 2021

Publisher's Note: MDPI stays neutral with regard to jurisdictional claims in published maps and institutional affiliations.

Copyright: (c) 2021 by the authors. Licensee MDPI, Basel, Switzerland. This article is an open access article distributed under the terms and conditions of the Creative Commons Attribution (CC BY) license (https:// creativecommons.org/licenses/by/ $4.0 /)$.
Boreskov Institute of Catalysis SB RAS, Lavrentieva Av. 5, 630090 Novosibirsk, Russia; simagina@catalysis.ru (V.I.S.); po4tar@catalysis.ru (A.A.P.); obulavchenko@catalysis.ru (O.A.B.); arcady.ishchenko@gmail.com (A.V.I.); odegova@catalysis.ru (G.V.O.); gorlova@catalysis.ru (A.M.G.); ozerova@catalysis.ru (A.M.O.); lil@catalysis.ru (I.L.L.); tes@catalysis.ru (E.S.T.); msa@catalysis.ru (S.A.M.); netskina@catalysis.ru (O.V.N.)

* Correspondence: komova@catalysis.ru; Tel.: +7-383-330-7458

Abstract: The paper presents a comparative study of the activity of magnetite $\left(\mathrm{Fe}_{3} \mathrm{O}_{4}\right)$ and copper and cobalt ferrites with the structure of a cubic spinel synthesized by combustion of glycine-nitrate precursors in the reactions of ammonia borane $\left(\mathrm{NH}_{3} \mathrm{BH}_{3}\right)$ hydrolysis and hydrothermolysis. It was shown that the use of copper ferrite in the studied reactions of $\mathrm{NH}_{3} \mathrm{BH}_{3}$ dehydrogenation has the advantages of a high catalytic activity and the absence of an induction period in the $\mathrm{H}_{2}$ generation curve due to the activating action of copper on the reduction of iron. Two methods have been proposed to improve catalytic activity of $\mathrm{Fe}_{3} \mathrm{O}_{4}$-based systems: (1) replacement of a portion of $\mathrm{Fe}^{2+}$ cations in the spinel by active cations including $\mathrm{Cu}^{2+}$ and (2) preparation of highly dispersed multiphase oxide systems, involving oxide of copper.

Keywords: ammonia borane; hydrolysis; hydrothermolysis; ferrite; copper; cobalt; magnetite; copper oxide

\section{Introduction}

Ammonia borane $\left(\mathrm{NH}_{3} \mathrm{BH}_{3}, \mathrm{AB}\right)$ is an extensively studied hydride and dozens of review articles have already appeared discussing the results of these studies [1-10]. The high hydrogen content of this hydride $(19.6 \mathrm{wt} \%)$ allows it to be applied in a variety of fields: as hydrogen storage systems to generate hydrogen for the needs of hydrogen economy [1-10], as a component of fuels [11,12], as a reducing agent in fine organic synthesis [13] and in the synthesis of metallic nanoparticles [14,15].

Different ways have been employed to release hydrogen from ammonia borane. Processes of its solid-state dehydrogenation from different hydride-containing materials have been described [5,7]. Processes of its dehydrogenation in organic solvents are also studied [16] (including with the use of catalysts [17]). Catalytic hydrolysis of AB is a simple and most widely used process (1):

$$
\begin{gathered}
\mathrm{NH}_{3} \mathrm{BH}_{3}+3 \mathrm{H}_{2} \mathrm{O} \rightarrow \mathrm{NH}_{3}+\mathrm{H}_{3} \mathrm{BO}_{3}+3 \mathrm{H}_{2} \uparrow \\
\mathrm{NH}_{3}+\mathrm{H}_{2} \mathrm{O} \leftrightarrow \mathrm{NH}_{4}^{+}+\mathrm{OH}^{-}
\end{gathered}
$$

This process is traditionally carried out in an excess of water at room temperature in the presence of various catalysts $[8-10,18,19]$. Because of the high content of water, this process has a low value of gravimetric hydrogen density (GHD $<1 \mathrm{wt} \%$ ), which is calculated using the ratio of the mass of released hydrogen to the total mass of all reactants and components of the hydrogen-generating system. 
Hydrothermolysis is another water-employing process for the release of hydrogen from $A B$ [20-23] where a highly exothermic process of AB hydrolysis (1) is coupled with its thermolysis (solid-state dehydrogenation) (2), (3):

$$
\begin{array}{ccc}
\mathrm{xNH}_{3} \mathrm{BH}_{3}=\left[\mathrm{NH}_{2} \mathrm{BH}_{2}\right]_{\mathrm{x}}+\mathrm{xH}_{2} \uparrow & \sim 100{ }^{\circ} \mathrm{C} & \mathrm{GHD}=6.5 \mathrm{wt} \% \\
{\left[\mathrm{NH}_{2} \mathrm{BH}_{2}\right]_{\mathrm{x}}=[\mathrm{NHBH}]_{\mathrm{x}}+\mathrm{xH}_{2} \uparrow} & \sim 150{ }^{\circ} \mathrm{C} & \mathrm{GHD}=13 \mathrm{wt} \%
\end{array}
$$

The process takes place with a high rate of hydrogen generation and with a high yield of hydrogen under the conditions when particles of the hydride wetted with a small quantity of water are heated in a reactor at a temperature of the external heating of $>80^{\circ} \mathrm{C}$. The addition of a catalyst facilitates an increase in the rate of hydrogen evolution and a reduce the temperature of the reactor heating [24,25]. Thus, high values of GHD of $>7 \mathrm{wt} \%$ have been achieved at relatively low temperatures. The effectiveness of the process is rather strongly dependent on the reactor design, the way of reactants loading into the reactor as well as on the conditions of the experiment.

Since $\mathrm{AB}$ is a reducer, using ex situ-reduced catalysts is not the only option in the dehydrogenation processes, but a catalytically active state of the catalysts can also be formed in situ using the compounds of active metals added in the reaction medium [26-29]. It has been found that the in situ-forming catalysts have higher activity [26-28]. Let us consider in more detail the use of oxides in the reactions of $A B$ hydrolysis.

An analysis of the literature shows that copper is one of the most important components of the catalysts for $\mathrm{AB}$ hydrolysis [10,30]. In 2008, Kalidindi et al. [26] showed the activity of the catalysts decreases in the order $\mathrm{Cu}_{2} \mathrm{O}>\mathrm{Cu} @ \mathrm{Cu}_{2} \mathrm{O}>\mathrm{Cu}$. It has been confirmed by $\mathrm{X}$-ray diffraction analysis (XRD) that, in the course of the reaction, a reduction of $\mathrm{Cu}_{2} \mathrm{O}$ to $\mathrm{Cu}^{0}$ occurs. It was suggested by the authors that the reduction of $\mathrm{Cu}_{2} \mathrm{O}$ in the reaction medium was accelerated by the formation of hydridic $\mathrm{Cu}-\mathrm{H}$ species. Later, the assumption that the ability of copper to be easily reduced in an aqueous solution of $\mathrm{AB}$ to form active $\mathrm{Cu}-\mathrm{H}$ species was confirmed in a series of studies exploring the activity of copper-containing cobalt oxides: $\mathrm{CuCo}_{2} \mathrm{O}_{4}$ [31,32], $\mathrm{Cu}_{0.6} \mathrm{Ni}_{0.4} \mathrm{Co}_{2} \mathrm{O}_{4}$ [33], $\mathrm{Co}_{0.92} \mathrm{Cu}_{0.08} \mathrm{Co}_{2} \mathrm{O}_{4} @ \mathrm{Co}_{0.88} \mathrm{Cu}_{0.12} \mathrm{Co}_{2} \mathrm{O}_{4}$ with a «yolk-shell» structure [34], Mo-doped $\mathrm{Cu}_{0.5} \mathrm{Ni}_{0.5} \mathrm{Co}_{2} \mathrm{O}_{4}$ [35]. In these studies, it was confirmed by $\mathrm{X}$-ray photoelectron spectroscopy (XPS) that the addition of copper accelerates the reduction of other metal cations comprising the complex oxide. This evidence was explained as follows: $\mathrm{Cu}^{2+}(0.337 \mathrm{~V}$ vs. SHE) are primarily reduced in the reaction medium to form $\mathrm{Cu}^{0}$ particles containing hydridic $\mathrm{Cu}-\mathrm{H}$ bonds on their surface. It is these active hydridic species that promote the reduction of other cations in the oxide. This results in the formation of a multi-component active state of the catalyst immobilized on the rest of the oxide matrix, showing a synergic effect in the AB hydrolysis. Such regularities have also been observed in the case of other complex oxides: $\mathrm{Co}_{0.8} \mathrm{Cu}_{0.2} \mathrm{MoO}_{4}$ [36] and $\mathrm{Co}_{3} \mathrm{O}_{4} / \mathrm{CuMnO}_{4}$ [37]. In the latter work, the copper of the $\mathrm{CuMnO}_{4}$ accelerated the formation of a cobalt-active component from the separated crystalline phase of $\mathrm{Co}_{3} \mathrm{O}_{4}$ contacting with $\mathrm{CuMnO}_{4}$. As a result, the induction period characterizing the long process of reduction of $\mathrm{Co}_{3} \mathrm{O}_{4}$ in the reaction medium disappeared [37]. A similar synergic effect has been observed for the nanosized particles of $\mathrm{Co}_{3} \mathrm{O}_{4}$, whose surface was doped by copper oxide [38] and in the the $\mathrm{CuO}-\mathrm{NiO} / \mathrm{Co}_{3} \mathrm{O}_{4}$ catalytic system [39].

Unlike the studied cobaltites and molybdates, the application perspectives of $\mathrm{Fe}_{3} \mathrm{O}_{4}$ and ferrrites of transition metals for the $\mathrm{AB}$ hydrolysis have not yet been completely investigated. Traditionally, these oxides have been proposed for applications such as magnetically removable supports [40-44]. To prevent the active component from interacting with the support, protecting the support surface using an inert layer of a polymer or silica was proposed. It was also shown that $\mathrm{CoFe}_{2} \mathrm{O}_{4}$ and $\mathrm{Fe}_{3} \mathrm{O}_{4}$ used as supports were themselves not active in this process [43,44].

The addition of copper into these oxides and its effect on the catalytic activity in the water-employing process of $\mathrm{AB}$ dehydrogenation remain practically unstudied. This is, in 
part, explained by the fact that in an article published in 2018 [45] - a series of metal ferrites prepared by precipitation were tested in the process of $\mathrm{AB}$ hydrolysis, showing rather low activity which increased in the order $\mathrm{NiFe}_{2} \mathrm{O}_{4}<\mathrm{CuFe}_{2} \mathrm{O}_{4}<\mathrm{ZnFe}_{2} \mathrm{O}_{4}<\mathrm{MnFe}_{2} \mathrm{O}_{4}$, i.e., nickel- and copper-ferrite-containing metals, usually active in the AB hydrolysisdemonstrated low activity. On the other hand, in 2016 the supported $\mathrm{CuFe}_{2} \mathrm{O}_{4} / \mathrm{rGO}$ (rGO is reduced graphene oxide) has been successfully used in the hydrolysis of $\mathrm{NaBH}_{4}$ [46], which is a stronger reducer than $\mathrm{AB}$.

Because of the lack of sufficient information on the ferrites of copper, in 2019, we started a series of further experiments [25], which confirmed the inactivity of $\mathrm{Fe}_{2} \mathrm{O}_{3}$ in the water-employing processes of $\mathrm{AB}$ dehydrogenation (hydrolysis (1), hydrothermolysis (1)-(3)); this occurred because $\mathrm{Fe}^{3+}$ were hardly reduced by a weak reducing agent such as $\mathrm{AB}$. The activity of $\mathrm{Fe}_{3} \mathrm{O}_{4}$ was higher, but the rate of hydrogen generation was extremely low. However, replacement of an amount of $\mathrm{Fe}^{2+}$ by $\mathrm{Cu}^{2+}$ allowed a large increase in activity both in the $\mathrm{AB}$ hydrolysis and $\mathrm{AB}$ hydrothermolysis. In $\mathrm{AB}$ hydrothermolysis $\left(90^{\circ} \mathrm{C}\right)$, the catalytic action of copper ferrite was observed both at the stage of hydrolysis and thermolysis. TEM and XRD analyses of the reaction products confirmed the reduction of copper ferrite in the reaction medium to form active nanosized particles $\mathrm{Fe}^{0}$ and $\mathrm{Cu}^{0}$. It was found that there is a relation between copper ferrite activity and its content of $\mathrm{Fe}^{2+}$. It was shown that the combustion of a glycine-nitrate precursor is an effective way to synthesize an active copper ferrite. Since its formation takes place at high temperatures and under conditions of a vigorous gas evolution limiting the access of air to the reaction zone, the structure of the forming cubic spinel has a larger content of $\mathrm{Fe}^{2+}$, which decreases when the annealing process begins $[25,47]$.

The present paper is a continuation of these studies. The study of the release of hydrogen from solutions of different hydrides $\left(\mathrm{NH}_{3} \mathrm{BH}_{3}, \mathrm{NaBH}_{4}\right.$, and $\left.\mathrm{NH}_{3} \mathrm{BH}_{3}+\mathrm{NaBH}_{4}\right)$ in the presence of combustion-synthesized cobalt and copper ferrites will once more emphasize the important role of the reduction rate offered by these oxides in the reaction medium. The synergic catalytic effect of the complex mixed $\mathrm{Cu}-\mathrm{Fe}$ and $\mathrm{Co}-\mathrm{Fe}$ oxides and the importance of further investigations of the active iron-containing component will be demonstrated. Comparing the activities of combustion products prepared under different synthesis conditions, and having different phase compositions, will help to reveal the key characteristics of an active catalyst (the content of the cubic spinel and the content of copper in its structure as well as the presence in the sample of active copper-containing impurity).

\section{Materials and Methods}

\subsection{Methods of Synthesis of the Samples under Study}

The reagents and the synthesis of the mixed oxides samples are described in the Supplementary Materials. The samples (CuFe-1, CuFe-2, CuFe-3, CuFe-4, CuFe-5, and $\mathrm{CoFe}$ ) were prepared by combustion of the glycine-nitrate precursors (Figures S1-S3 in the Supplementary Materials). For these combustion products, the values of specific surface area $\left(S_{\mathrm{BET}}\right)$ were $\leq 7 \mathrm{~m}^{2} \cdot \mathrm{g}^{-1}$, the $\mathrm{M} / \mathrm{Fe}$ molar ratios $(\mathrm{M}=\mathrm{Cu}, \mathrm{Co})$ were $0.43 \pm 0.01$ (the details see Supplementary Materials).

The $\mathrm{Fe}_{3} \mathrm{O}_{4}$ sample $\left(\mathrm{S}_{\mathrm{BET}}=15 \mathrm{~m}^{2} \cdot \mathrm{g}^{-1}\right)$ was prepared by the traditional procedure of precipitation from $\mathrm{FeSO}_{4} \cdot 7 \mathrm{H}_{2} \mathrm{O}$ and $\mathrm{FeCl}_{3} \cdot 6 \mathrm{H}_{2} \mathrm{O}$ with molar ratio of $\mathrm{Fe}^{3+} / \mathrm{Fe}^{2+}=2$ as described in [25]. The XRD analysis of dried sample confirmed that the observed diffraction pattern corresponded to the structure of $\mathrm{Fe}_{3} \mathrm{O}_{4}$ [PDF 26-1136], the coherent scattering region $(\mathrm{CSR})$ was $11 \mathrm{~nm}$. The $\mathrm{CuO}$ sample $\left(\mathrm{S}_{\mathrm{BET}}=49 \mathrm{~m}^{2} \cdot \mathrm{g}^{-1}\right)$ was prepared by annealing $\mathrm{CuCO}_{3} \cdot \mathrm{Cu}(\mathrm{OH})_{2}$ at $300{ }^{\circ} \mathrm{C}$ for $4 \mathrm{~h}$. The observed XRD patterns of the product fully corresponded to those of $\mathrm{CuO}$ [PDF 45-937]. The CSR was $10 \mathrm{~nm}$. To prepare the $10 \mathrm{wt} \% \mathrm{CuO} / \mathrm{Fe}_{3} \mathrm{O}_{4}$ composite, $0.3 \mathrm{~g}$ of $\mathrm{Fe}_{3} \mathrm{O}_{4}$ and $0.0927 \mathrm{~g}$ of $\mathrm{CuCO}_{3} \cdot \mathrm{Cu}(\mathrm{OH})_{2}$ were mixed in a mortar and annealed at $300{ }^{\circ} \mathrm{C}$ for $4 \mathrm{~h}$. The $\mathrm{S}_{\mathrm{BET}}$ and CSR for $\mathrm{Co}_{3} \mathrm{O}_{4}$ reagent (GOST 4467-79, SoyuzKhimProm, Novosibirsk, Russia) used in this study were $16 \mathrm{~m}^{2} / \mathrm{g}$ and $60 \mathrm{~nm}$, consequently. 


\subsection{Methods of Investigations}

Attenuated total reflection infrared spectroscopy (ATR FTIR) was performed on an Agilent Cary 600 (Agilent Technologies, Santa Clara, CA, USA) spectrometer equipped with a Gladi ATR (PIKE Technologies, Madison, WI, USA) attachment in the range $240-10,000 \mathrm{~cm}^{-1}$ without a pretreatment of the samples.

X-ray diffraction analysis (XRD) was performed on a Bruker D8 Advance diffractometer (Bruker AXS GmbH, Karlsruhe, Germany) in the range of angles $10-80^{\circ}$ with a step $2 \theta=0.05^{\circ}$ and the time of accumulation of $5 \mathrm{~s}$ in each point using a Lynxeye linear detector. $\mathrm{CuK}_{\alpha}$ radiation $(\lambda=1.5418 \AA)$ was used. A quantitative phase analysis has been performed by the Rietveld method. The results are presented in Tables 1 and 2 . The average coherent scattering regions were determined using the Scherrer formula from the following reflections: 311 for cubic spinel $\left(\mathrm{Fe}_{3} \mathrm{O}_{4}, \mathrm{M}_{1-\mathrm{x}} \mathrm{Fe}_{2+\mathrm{x}} \mathrm{O}_{4} \mathrm{M}=\mathrm{Cu}\right.$ or $\left.\mathrm{Co}\right), 111$ for $\mathrm{CuO}, 111$ for $\mathrm{Cu}, 104$ for $\mathrm{Fe}_{2} \mathrm{O}_{3}, 111$ for $\mathrm{Cu}_{2} \mathrm{O}, 600$ for $\mathrm{CuFeO}_{2}, 311$ for $\mathrm{Co}_{3} \mathrm{O}_{4}$, and 111 for $\mathrm{CoO}$. The phases were identified using the following data: $\mathrm{CuFe}_{2} \mathrm{O}_{4}$ [PDF 25-283], $\mathrm{CoFe}_{2} \mathrm{O}_{4}$ [PDF 22-1686], $\mathrm{Fe}_{3} \mathrm{O}_{4}$ [PDF 26-1136], $\mathrm{CuO}$ [PDF 45-937], $\mathrm{Cu}_{2} \mathrm{O}$ [PDF 5-667], $\mathrm{Cu}$ [PDF 4-836], $\mathrm{Fe}_{2} \mathrm{O}_{3}$ [PDF 33-664], $\mathrm{CuFeO}_{2}$ [ICSD 98488], $\mathrm{CoO}$ [PDF 42-1300], $\mathrm{Co}$ (cub.) [PDF 15-0806], $\mathrm{Co}_{3} \mathrm{O}_{4}$ [PDF 42-1267].

Table 1. The comparison the results of X-ray diffraction (XRD) method and differential dissolution (DD) for the samples of copper and cobalt ferrites prepared by combustion synthesis.

\begin{tabular}{|c|c|c|}
\hline Sample & XRD (wt\%) & $\mathrm{DD}\left(w \mathrm{t}^{\%}\right)^{1}$ \\
\hline CuFe-1 & $\begin{array}{c}84 \% \mathrm{Cu}_{1-\mathrm{x}} \mathrm{Fe}_{2+\mathrm{x}} \mathrm{O}_{4} \text { (cub. spinel) } \\
\mathrm{CSR}=62 \mathrm{~nm} \\
13 \% \mathrm{CuFeO} \mathrm{CSR}_{2} \mathrm{CSR} 130 \mathrm{~nm} \\
3 \% \mathrm{CuO}\end{array}$ & $\begin{array}{c}75.9 \% \mathrm{Cu}_{0.29} \mathrm{Fe}_{1}{ }^{2} \\
14.4 \% \mathrm{Cu}_{1} \\
9.7 \% \mathrm{Fe}_{1}\end{array}$ \\
\hline $\mathrm{CoFe}$ & $\begin{array}{c}90 \% \mathrm{Co}_{1-x} \mathrm{Fe}_{2+x} \mathrm{O}_{4} \text { (cub. spinel) } \\
\mathrm{CSR}=93 \mathrm{~nm} \\
8 \% \mathrm{CoO} \mathrm{CSR}=40 \mathrm{~nm} \\
3 \% \mathrm{Co}(\text { cub. })\end{array}$ & $\begin{array}{c}87.4 \% \mathrm{Co}_{0.43} \mathrm{Fe}_{1}{ }^{3} \\
8.2 \% \mathrm{Co}_{1} \\
4.4 \% \mathrm{Fe}_{1}\end{array}$ \\
\hline
\end{tabular}

${ }^{1}$ Since oxygen is not determined by the DD method, the stoichiometric formulas of the corresponding phases are traditionally presented without oxygen. ${ }^{2}$ Corresponds to $\mathrm{Cu}_{0.67} \mathrm{Fe}_{2.33} \mathrm{O}_{4}$ formula. ${ }^{3}$ Corresponds to $\mathrm{Co}_{0.90} \mathrm{Fe}_{2.10} \mathrm{O}_{4}$ formula.

Table 2. The results of X-ray diffraction method and specific surface values for the different combustion products obtained in different regimes.

\begin{tabular}{|c|c|c|c|}
\hline $\mathbf{N}^{\circ}$ & Sample & $\mathrm{S}_{\mathrm{BET}}\left(\mathrm{m}^{2} / \mathrm{g}\right)$ & Phase Composition (wt $\%$ ) \\
\hline 1 & CuFe-1 & 4 & $\begin{array}{c}\text { 84\% spinel (cub.) CSR = } 62 \mathrm{~nm} \\
3 \% \mathrm{CuO} \\
13 \% \mathrm{CuFeO}_{2} \mathrm{CSR}=130 \mathrm{~nm}\end{array}$ \\
\hline 2 & $\mathrm{CuFe}-2$ & 7 & $\begin{array}{c}73 \% \text { spinel (cub.) CSR = } 49 \mathrm{~nm} \\
6 \% \mathrm{Cu} \mathrm{CSR}>150 \mathrm{~nm} \\
12 \% \mathrm{CuOCSR}=20 \mathrm{~nm} \\
9 \% \mathrm{Fe}_{2} \mathrm{O}_{3} \mathrm{CSR}=31 \mathrm{~nm}\end{array}$ \\
\hline 3 & $\mathrm{CuFe}-3$ & 7 & $\begin{array}{c}66 \% \text { spinel (cub.) CSR = } 52 \mathrm{~nm} \\
14 \% \mathrm{Cu} \mathrm{CSR} \mathrm{>} 150 \mathrm{~nm} \\
6 \% \mathrm{CuO} \\
8 \% \mathrm{Fe}_{2} \mathrm{O}_{3} \mathrm{CSR}=54 \mathrm{~nm} \\
6 \% \mathrm{CuFeO}_{2}\end{array}$ \\
\hline 4 & $\mathrm{CuFe}-4$ & 3 & $\begin{array}{c}48 \% \text { spinel (cub.) CSR = } 62 \mathrm{~nm} \\
15 \% \mathrm{Cu} \mathrm{SCR}>150 \mathrm{~nm} \\
6 \% \mathrm{Cu}_{2} \mathrm{O} \\
26 \% \mathrm{Fe}_{2} \mathrm{O}_{3} \mathrm{CSR}=93 \mathrm{~nm} \\
5 \% \mathrm{CuFeO}_{2}\end{array}$ \\
\hline 5 & $\mathrm{CuFe}-5$ & $<1$ & $\begin{array}{c}34 \% \text { spinel (cub.) CSR = } 77 \mathrm{~nm} \\
18 \% \mathrm{Cu} C S R>150 \mathrm{~nm} \\
7 \% \mathrm{Cu}_{2} \mathrm{O} C S R=28 \mathrm{~nm} \\
40 \% \mathrm{Fe}_{2} \mathrm{O}_{3} \mathrm{SCR}=71 \mathrm{~nm}\end{array}$ \\
\hline
\end{tabular}


The structure of the samples was studied by high-resolution transmission electron microscopy (HRTEM) using a ThemisZ electron microscope (Thermo Fisher Scientific, Waltham, MA, USA) with an accelerating voltage of $200 \mathrm{kV}$ and a limiting resolution of $0.07 \mathrm{~nm}$. Elemental maps were obtained using energy dispersive spectrometer SuperX Thermo Fisher Scientific. Samples for research were fixed on standard aluminum grid using ultrasonic dispersion in ethanol. The scanning electron microscopy (SEM) images were obtained with a JEOL JSM-6460 LV (Jeol, Akishima, Japan) instrument.

The specific surface area $\left(\mathrm{S}_{\mathrm{BET}}\right)$ was determined by desorption of argon using a SorbiM instrument (Meta, Novosibirsk, Russia).

The $\mathrm{Cu}$, Co and Fe contents were determined by atomic-emission spectrometry with inductively coupled plasma (ICP-AES) using Optima 4300 DV instrument (Perkin Elmer, Shelton, CT 06484-4794, USA).

The differential dissolution (DD) of the combustion products was performed under a flow dynamic regime using the stoichiograph equipped with inductively coupled plasma atomic emission (ICP AES) spectrometer (Baird, Zoeterwoude, Netherlands) [48]. In this method, identification of the phases is based on their different solubilities when the temperature and acidity of the solvent were changed as the process of dissolution went on in time. A powder of the combustion product $(\approx 10 \mathrm{mg})$ was spread over a disposable support made from a sticky polymeric film and transferred into a flow microreactor for dissolution in a flow of solvent (at a flow rate of $3.6 \mathrm{~mL} \cdot \mathrm{min}^{-1}$ ). The process was started with an aqueous solution of $0.01 \mathrm{M} \mathrm{HCl}(\mathrm{Ph}=2)$, which was gradually replaced by $1.2 \mathrm{M}$ $\mathrm{HCl}, 3 \mathrm{M} \mathrm{HCl}$ and $4 \mathrm{M} \mathrm{HF}$ (Figure S4 in the Supplementary Materials). The reactor temperature was gradually raised from 22 to $80{ }^{\circ} \mathrm{C}$. The elemental composition of solvent was determined every $5 \mathrm{~s}$ from the spectral lines: $324.7 \mathrm{~nm}(\mathrm{Cu}), 238.2 \mathrm{~nm}(\mathrm{Fe})$, and $238.8 \mathrm{~nm}(\mathrm{Co})$ with a sensitivity of $10^{-3} \mu \mathrm{g} / \mathrm{mL}$ and an error of determination of $\leq 5 \%$. The kinetic dissolution curves of the elements were transformed into stoichiograms (molar ratios of the elements) (Figure S5). Mathematical processing of the obtained results allows the content and stoichiometric composition of the mixed oxide to be determined, as well as the contents of impurity phases which were obtained by subtracting the main phase of the mixed oxide from the overall curves of the dissolved elements (Figures S5 and S6) [49]. The stoichiometric formula of the mixed phase without oxygen was determined using the average values for selected segment of the stoichiogram with a standard relative deviation of less than $10 \%$ and calculated over several tens of the measured points (Figure S5).

\subsection{Procedures of $\mathrm{NH}_{3} \mathrm{BH}_{3}$ Dehydrogenation}

$\mathrm{NH}_{3} \mathrm{BH}_{3}(93 \%)$ was prepared and characterized as described in [24]. According to XRD, the average size of the CSR was $70 \mathrm{~nm}$. The particle size of the hydride was within $0.2-0.4 \mathrm{~mm}$. The experimental details of the AB hydrolysis and hydrothermolysis have been described in [23-25]. The volume of the released hydrogen was measured by the water displacement method in a gas burette. The obtained values were reduced to the N.T.P. and expressed in mole equivalents of the hydrogen released from one mole of $\mathrm{NH}_{3} \mathrm{BH}_{3}$.

The $\mathrm{AB}$ hydrolysis was carried out at 40 and $60{ }^{\circ} \mathrm{C}$ under stirring. First, $10 \mathrm{~mL}$ of distilled water was added into a glass reactor $(\mathrm{V}=52.5 \mathrm{~mL})$ preheated to the required temperature; then, $\mathrm{AB}(38 \mathrm{mg})$ and the catalyst powder $(11.7 \mathrm{mg})$ were quickly added in succession. The evolving hydrogen was passed through a condenser to the gas burette $(100 \mathrm{~mL})$. To establish the effect of the reducing power of the hydride on the rate of activation of the catalyst in the reaction medium and hydrogen evolution, in similar hydrolysis experiments, $\mathrm{NH}_{3} \mathrm{BH}_{3}$ was replaced by $\mathrm{NaBH}_{4}(46.5 \mathrm{mg})$ and by $\mathrm{NH}_{3} \mathrm{BH}_{3}$ (32.4 mg) with a small content of $\mathrm{NaBH}_{4}(6.8 \mathrm{mg})$.

In the hydrothermolysis experiments, a mechanical mixture of $46 \mathrm{mg}$ of $\mathrm{NH}_{3} \mathrm{BH}_{3}$ and $5.2 \mathrm{mg}$ of the oxide powder $(10 \mathrm{wt} \%)$ was loaded into a glass reactor $(\mathrm{V}=32 \mathrm{~mL})$ to which distilled water was then added in drops using a micropipette $(54 \mu \mathrm{L})$ until a molar ratio of $\mathrm{H}_{2} \mathrm{O} / \mathrm{AB}=2$ was achieved. The sealed reactor was immersed into an oil bath preheated to $90 \pm 1{ }^{\circ} \mathrm{C}$. In the course of the experiments, the temperature inside the reaction layer and 
the volume of the evolving hydrogen were measured. Before going to the gas burette, the evolved hydrogen was passed through a trap filled with a $5 \%$ solution of $\mathrm{CuSO}_{4}$.

\section{Results and Discussion}

3.1. Comparison of the Activities of Cobalt, Copper and Iron Oxides in $\mathrm{NH}_{3} \mathrm{BH}_{3}$ Thermolysis and Hydrothermolysis

To confirm the promoting action of copper on the reduction of iron in the reaction media of $\mathrm{AB}$ hydrolysis and hydrothermolysis, ferrites of copper (CuFe-1) and cobalt (CoFe) have been prepared by combustion of glycine-nitrate precursors (Figures S1 and S3 in the Supplementary Materials) and characterized by ATR FTIR, XRD, DD and SEM. The micrographs (Figure 1) of the obtained combustion products indicated that they have close sizes of their particles and for the most part consist of micro-porous particles with a size smaller than $100 \mu \mathrm{m}$. The $\mathrm{S}_{\mathrm{BET}}$ for $\mathrm{CuFe}-1$ and $\mathrm{CoFe}$ was also the same $\left(4 \mathrm{~m}^{2} / \mathrm{g}\right)$.
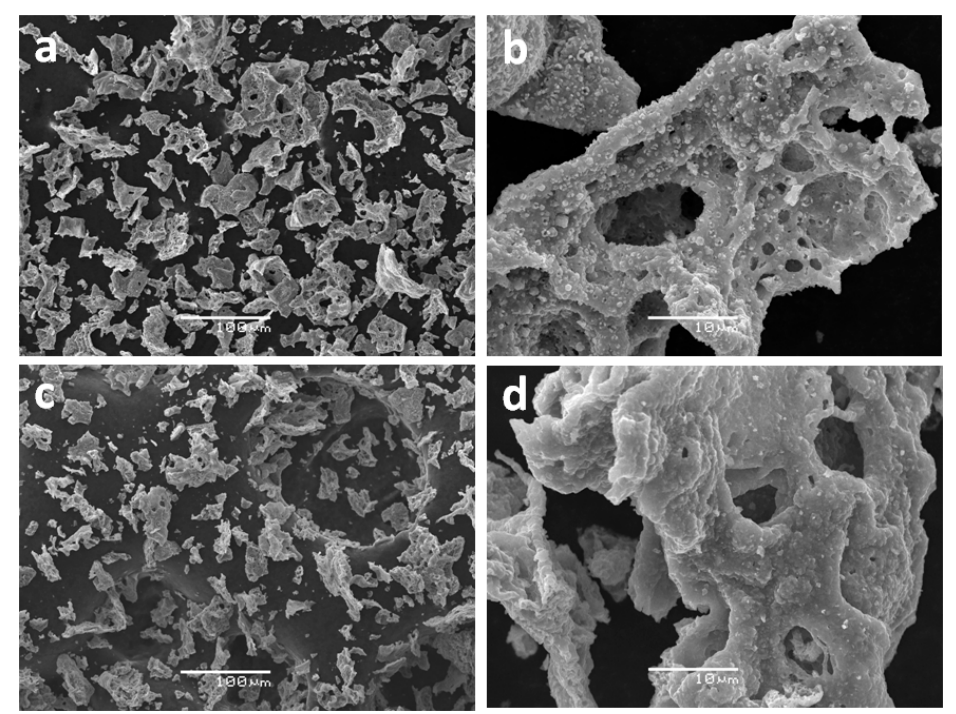

Figure 1. The SEM images of (a,b) copper ferrite $(\mathrm{CuFe}-1)$ and $(\mathbf{c}, \mathbf{d})$ cobalt ferrite $(\mathrm{CoFe})$ prepared by combustion method.

In Table 1, the results of the XRD phase analysis are compared with those obtained by DD. Note that, when using XRD, it is more difficult to distinguish between the cubic spinel of $\mathrm{Fe}_{3} \mathrm{O}_{4}$ and those of $\mathrm{Cu}_{1-\mathrm{x}} \mathrm{Fe}_{2+\mathrm{x}} \mathrm{O}_{4}$ and $\mathrm{Co}_{1-\mathrm{x}} \mathrm{Fe}_{2+\mathrm{x}} \mathrm{O}_{4}$ because of the close parameters of their crystalline structures. The advantages of the combined use of XRD and DD have been demonstrated earlier [25], where DD was used to determine the stoichiometry and content of the main phase of the cubic spinel. The contents of the impurity phases were calculated, as were the rest of the remaining substances, after subtraction of the main phase from the overall dissolution curves of the determined elements.

Using the results obtained by XRD (Table 1) and DD (Figures S5-S7), it is demonstrated that the main phase of the combustion products is a spinel with a cubic structure $\left(\mathrm{Cu}_{0.67} \mathrm{Fe}_{2.33} \mathrm{O}_{4}\right.$ or $\left.\mathrm{Co}_{0.90} \mathrm{Fe}_{2.10} \mathrm{O}_{4}\right)$. Apart from the main phase of the cubic spinel, these methods also reveal the presence of other phases of copper, cobalt and iron. Cobalt ferrite has smaller contents of such impurity phases and, hence, more cobalt is found in the structure of the spinel. We believe this to be associated with the fact that, under the conditions of the vigorous combustion and a limited access of air to the reaction zone, $\mathrm{Co}^{2+}$ is less capable of being reduced, which allows it to enter the spinel lattice.

The ATR FTIR spectra in the region of metal-oxygen vibrations are shown in Figure 2a. As in the spectrum of $\mathrm{Fe}_{3} \mathrm{O}_{4}$, the spectra of CuFe-1 and CoFe clearly reveal the presence of two intense absorption bands at $700-500 \mathrm{~cm}^{-1}$ and $470-260 \mathrm{~cm}^{-1}$, which were to the vibrations of iron in the tetrahedral $\left[\mathrm{FeO}_{4}\right]$ and octahedral $\left[\mathrm{FeO}_{6}\right]$ environments, respectively $[50,51]$. In the case of ferrites, the shifts in the centers of gravity of these bands are 
associated with the influence of the copper or cobalt cations on the vibrations of iron, as well as with the possible reduction of the spinel cations leading to the change of the Fe-O bonds [52]. These changes are most characteristic of the vibrations of $\left[\mathrm{FeO}_{6}\right]$. A more detailed analysis of Fe-containing spinel spectra was given in our previous paper [25].

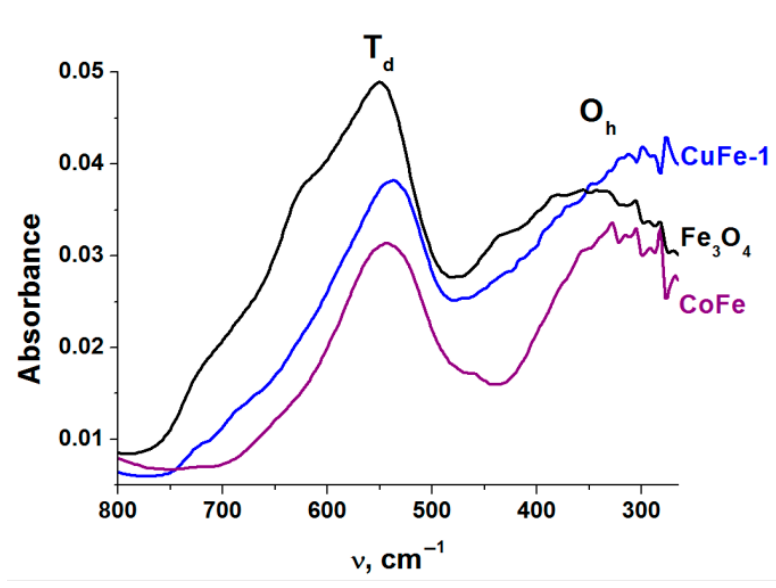

(a)

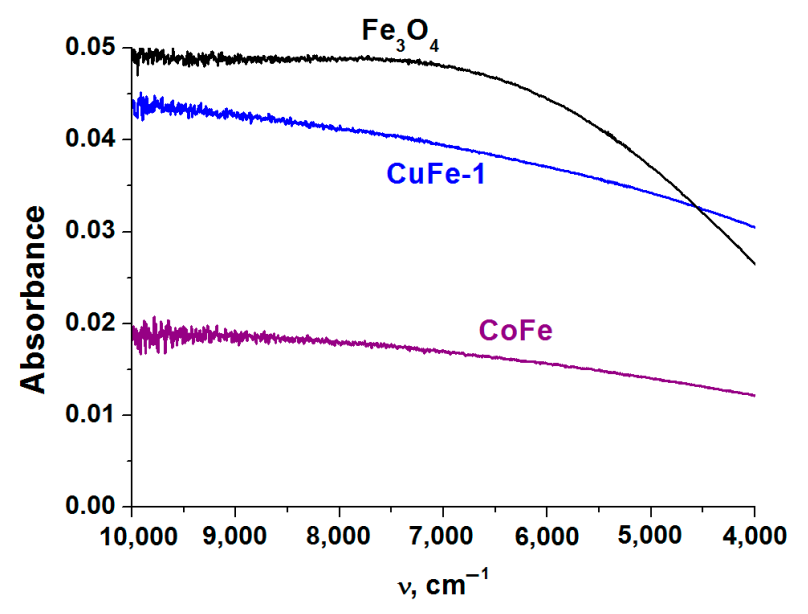

(b)

Figure 2. The spectra of $\mathrm{Fe}_{3} \mathrm{O}_{4}$, copper ferrite (CuFe-1) and cobalt ferrite (CoFe) in the region of vibrations of metal-oxygen bonds (a) and in the near-infrared region $(\mathbf{b})$.

The higher content of cobalt in the cobalt ferrite as compared with the content of copper in the copper ferrite suggests that there will be a low content of $\mathrm{Fe}^{2+}$ in the structure of the cobalt-containing spinel. This suggestion is confirmed by the ATR FTIR spectra in the near-IR region (Figure 2b). It is known that the absorption in this region characterizes the electronic conductivity in $\mathrm{Fe}_{3} \mathrm{O}_{4}$ due to the constant exchange of electrons between $\mathrm{Fe}^{2+}$ and $\mathrm{Fe}^{3+}$ in the closely lying octahedral positions [53]. The lower level of absorption in the case of CoFe sample confirms the greater extent of the $\mathrm{Fe}^{2+}$ replacement by $\mathrm{Co}^{2+}$ in this spinel.

As seen in the results shown in Figure 3, in the case of copper and cobalt ferrites, the rates of hydrogen generation are higher than in the case of individual oxides. Note that $\mathrm{CuO}, \mathrm{Co}_{3} \mathrm{O}_{4}$, and $\mathrm{Fe}_{3} \mathrm{O}_{4}$ have higher specific surface areas than $\mathrm{CuFe}-1$ and $\mathrm{CoFe}$. On the contrary, this should improve their interaction with the reaction medium. Considering the low activity of $\mathrm{Fe}_{3} \mathrm{O}_{4}$, higher rates of hydrogen generation in the presence of ferrites are achieved at lower contents of copper or cobalt in the reaction medium than in the case of the oxides of these metals. This indicates a synergic action of the metals comprising the spinel. It should also be noted that the curves of hydrogen generation in the presence of the studied compounds of cobalt show the presence of an induction period (Figure 3). Earlier, when studying the $\mathrm{Co}_{3} \mathrm{O}_{4}$-catalyzed hydrolysis of $\mathrm{NaBH}_{4}$ and $\mathrm{NH}_{3} \mathrm{BH}_{3}$, the presence of the induction period has been explained by the slow reduction of cobalt oxide in the reaction medium to form active nanosize cobalt borides [29]. The absence of an induction period in the case of the copper-containing oxides indicates a faster activation of the catalyst in the reaction medium.

The activation behavior of the ferrites of copper and cobalt in the process of $A B$ hydrolysis (Figure 3) repeats itself in the stage of hydrolysis in another process-AB hydrothermolysis (Figure 4). We believe that the shorter induction period in the case of $\mathrm{CoFe}$ is associated with the higher temperatures of the reactor heating used in this process and the higher concentration of the hydride in the reaction medium. As expected, this confirms the earlier-established correlation between the rate of the AB hydrolysis stage and the time during which the process proceeds to the next stage of the $A B$ thermolysis [23-25]. The catalytic systems which were more active in the $A B$ hydrolysis are characterized by faster rates of hydrogen generation and higher yields of hydrogen in the first exothermic 
stage of $\mathrm{AB}$ hydrolysis, which provides a faster transition from the stage of hydrolysis to the stage of thermolysis (Figure 4).

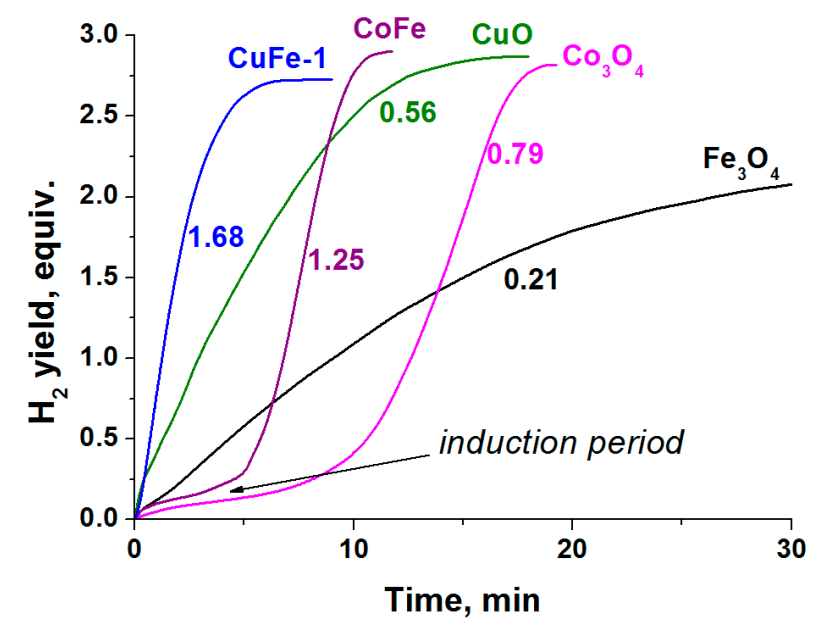

Figure 3. The influence of oxides on the hydrogen generation during catalytic hydrolysis of $\mathrm{NH}_{3} \mathrm{BH}_{3}(0.123 \mathrm{M})$ at $60^{\circ} \mathrm{C}$. The numbers indicate the attainable rate of $\mathrm{H}_{2}$ generation expressed as $\mathrm{L}_{\mathrm{H} 2} \cdot \mathrm{min}^{-1} \cdot \mathrm{g}^{-1}$ cat.

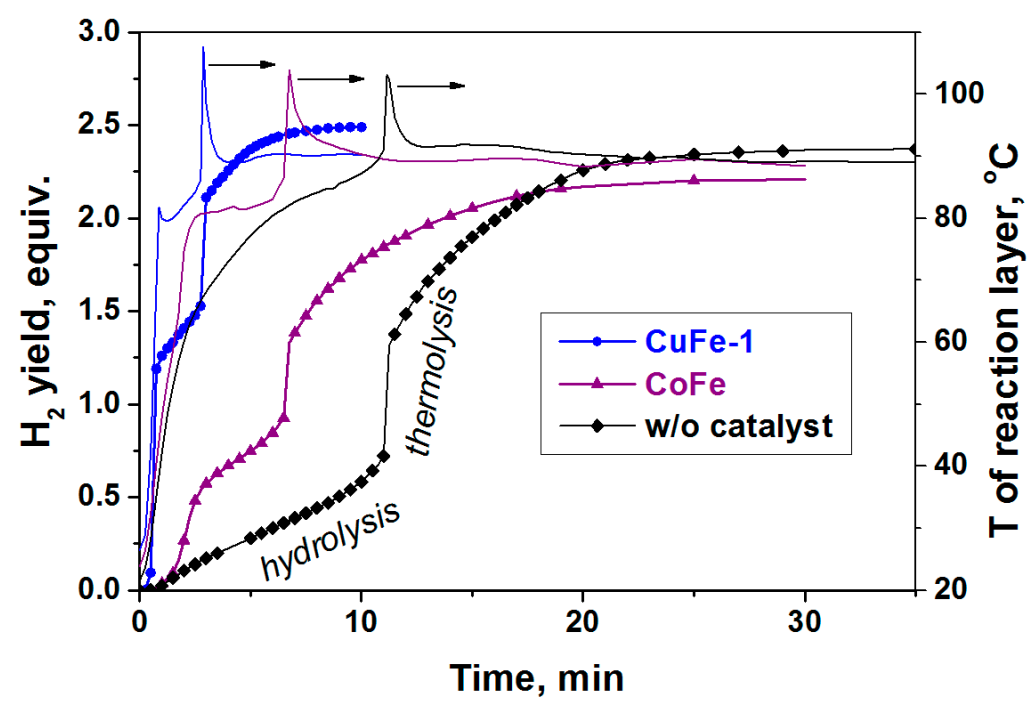

Figure 4. The influence of ferrites on hydrogen generation (symbol + line) and temperature of reaction layer (line) during the catalytic hydrothermolysis of $\mathrm{NH}_{3} \mathrm{BH}_{3}$ at external heating of reactor at $90{ }^{\circ} \mathrm{C}$ and a molar ratio of $\mathrm{H}_{2} \mathrm{O} / \mathrm{NH}_{3} \mathrm{BH}_{3}=2$.

The important role of the stage of oxide reduction has been demonstrated in experiments, where $\mathrm{CuFe}-1$ and $\mathrm{CoFe}$ samples have been tested in the hydrolysis of $\mathrm{NH}_{3} \mathrm{BH}_{3}, \mathrm{NaBH}_{4}$ and $\mathrm{NH}_{3} \mathrm{BH}_{3}$ with a small content of $\mathrm{NaBH}_{4}$ (Figure 5). These experiments were carried out at a lower temperature $\left(40^{\circ} \mathrm{C}\right)$ in order to lengthen the time of the induction period.

Ammonia borane is known to be a considerably weaker reducer than sodium borohydride [14,29]. The addition of ammonia borane to a small amount of $\mathrm{NaBH}_{4}$ enhances the formation of the active component in the reaction medium $[29,54]$ It is seen (Figure 5) that the most remarkable changes were in the case of cobalt ferrite where the stronger reducing power of the reaction medium resulted in an almost ten times shorter induction period in the hydrogen generation curve. The highest rate of hydrogen generation was in the case of the solution of $\mathrm{NaBH}_{4}$. In moving from $\mathrm{NH}_{3} \mathrm{BH}_{3}$ to $\mathrm{NH}_{3} \mathrm{BH}_{3}+\mathrm{NaBH}_{4}$ and $\mathrm{NaBH}_{4}$ solutions, the time of the reaction in the presence of CoFe was reduced from $32 \mathrm{~min}$ to $23 \mathrm{~min}$ and $11 \mathrm{~min}$, respectively. The changes in the case of CuFe-1 were less 
pronounced (Figure 5). The time of the reaction shortened from $13 \mathrm{~min}\left(\mathrm{NH}_{3} \mathrm{BH}_{3}\right)$ to $12 \mathrm{~min}$ $\left(\mathrm{NH}_{3} \mathrm{BH}_{3}+\mathrm{NaBH}_{4}\right)$ and $8.5 \mathrm{~min}\left(\mathrm{NaBH}_{4}\right)$. Overall, these results show that the product of combustion consisting predominantly of the copper-doped cubic spinel $\mathrm{Cu}_{0.67} \mathrm{Fe}_{2.33} \mathrm{O}_{4}$ shows considerable advantages over the $\mathrm{Co}_{0.90} \mathrm{Fe}_{2.10} \mathrm{O}_{4}$. Based on our results and the results reported in the literature such a behavior may, in the first place, be explained by the ability of copper ferrite to reduce in the reaction medium to form a catalytically active phase consisting of nanosized $\mathrm{Fe}^{0}$ and $\mathrm{Cu}^{0}$. The results of the above-made comparison of the activities of cobalt and copper ferrites once more confirm the assumption reported in the literature that the reduction of iron in the oxide structure is accelerated by the forming $\mathrm{Cu}-\mathrm{H}$ species which have a high hydrogenation power [10]. It allows us to suggest that the formation of the hydridic $\mathrm{Cu}-\mathrm{H}$ species is of importance not only during the stage of catalyst activation but also in the subsequent stage of the active generation of hydrogen because they slow down the oxidation of the nanosized active component in the aqueous reaction medium.

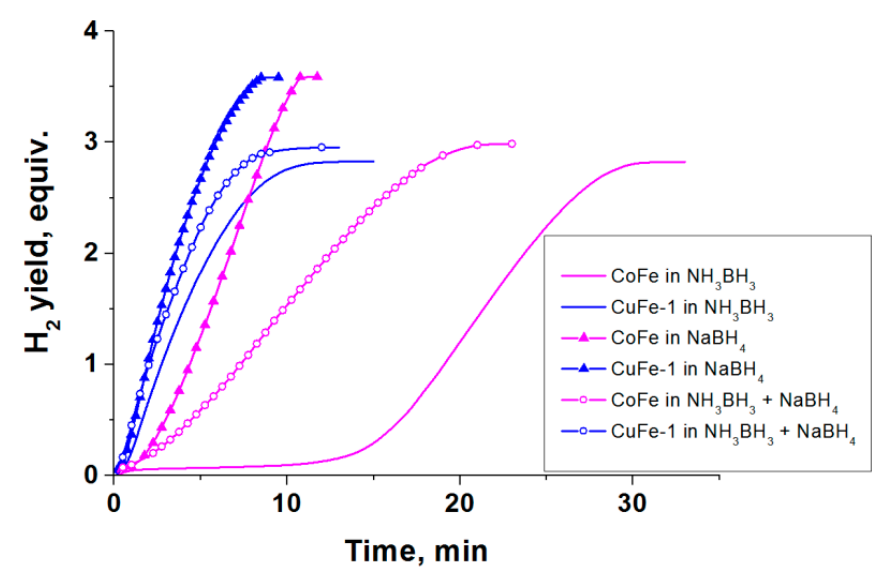

Figure 5. The effect of reductive ability of hydride medium on the hydrogen generation during catalytic hydrolysis of solutions of $\mathrm{NH}_{3} \mathrm{BH}_{3}(0.123 \mathrm{M}), \mathrm{NaBH}_{4}(0.123 \mathrm{M})$ and $\mathrm{NH}_{3} \mathrm{BH}_{3}(0.105 \mathrm{M})$ with $\mathrm{NaBH}_{4}(0.018 \mathrm{M})$ over copper and cobalt ferrites at $40^{\circ} \mathrm{C}$.

In the next section, the activity in the processes of $\mathrm{AB}$ hydrolysis and hydrothermolysis will be compared for combustion products which were synthesized under different conditions. As a result, the formed combustion products differed in the dispersity, the content of the cubic spinel, the content of $\mathrm{Cu}$ in the spinel structure and the content of the impurities. Analysis of these results allowed us to obtain more detailed characteristics of the active catalytic additive.

\subsection{Effect of the Phase Composition of Products of Combustion of Copper-Iron-Glycine-Nitrate Precursors on Their Activity in $\mathrm{NH}_{3} \mathrm{BH} 3$ Hydrolysis and Hydrothermolysis}

As can be seen from Table 2, the prepared products of combustion of copper-ironglycine-nitrate precursors differ in the content of the cubic spinel, CSR and the content and composition of impurities. For all samples, the $\mathrm{Cu} / \mathrm{Fe}$ molar ratios determined by ICP-AES were close $0.43 \pm 0.01$.

The results presented in Figure 6, Figure 7 show that the method of preparation and the characteristics of the combustion products determine their activity in the AB hydrolysis and hydrothermolysis. As expected, the behavior in the AB hydrolysis (Figure 6) repeats itself in the case of $\mathrm{AB}$ hydrothermolysis (Figure 7). To find out the most significant parameters of the combustion products, consisting not only of the phase of the cubic spinel but also contain other phases (Table 2), let us first consider the correlation between the product's activity and its characteristics for two of the studied combustion products: the most active sample, $\mathrm{CuFe}-1$, and the least active sample, $\mathrm{CuFe}-5$. 


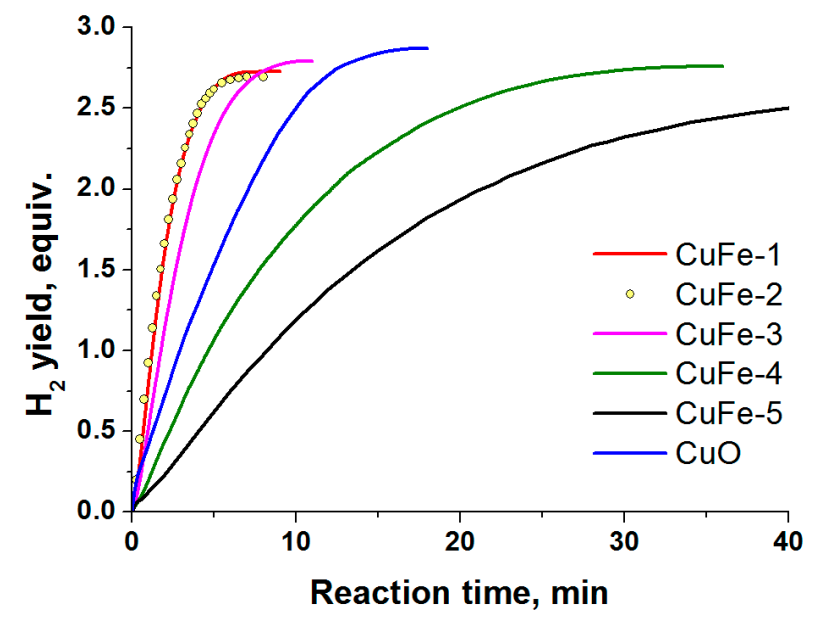

Figure 6. The activity of CuFe-combustion products (Table 2) in the catalytic hydrolysis of $\mathrm{NH}_{3} \mathrm{BH}_{3}$ $(0.123 \mathrm{M})$ at $60^{\circ} \mathrm{C}$.

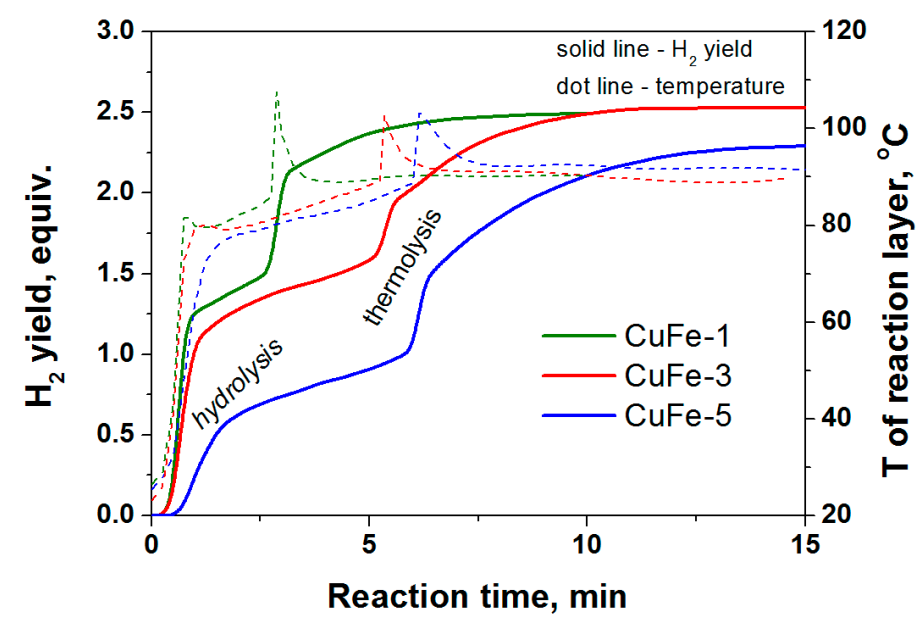

Figure 7. The activity of CuFe-combustion products (Table 2) in the catalytic hydrothermolysis of $\mathrm{NH}_{3} \mathrm{BH}_{3}$ at external heating of reactor at $90{ }^{\circ} \mathrm{C}$ and molar ratio of $\mathrm{H}_{2} \mathrm{O} / \mathrm{NH}_{3} \mathrm{BH}_{3}=2$. The solid lines are the hydrogen generation curves; the dotted lines are curves of temperature of reaction medium.

Let us start with the size of the particles. The SEM analysis (Figure S9) has shown the particles of the little active $\mathrm{CuFe}-5$ sample were the most sintered ones. This is also confirmed by the highest value of CSR for the phase of the cubic spinel (Table 2). Apart from its small dispersity, the least active sample $\mathrm{CuFe}-5$ shows the lowest content of the cubic spinel (34\%), the highest content of $\mathrm{Fe}_{2} \mathrm{O}_{3}(40 \%)$ and a high content of copper in the form of individual phases $\left(\mathrm{Cu}^{0}+\mathrm{Cu}_{2} \mathrm{O}\right)$. As we showed earlier [47], the formation the mixed copper-iron oxide phase in the case of this sample is complicated not only by the short time available for the components to interact in the reaction zone but also by the high temperatures in the reaction zone and the reduction of copper under the conditions of the vigorous gas evolution which decreases the content of oxygen in the reaction zone. This causes the copper to leave the structure of the spinel $[55,56]$.

The phase of the cubic spinel found by XRD is attributable both to the small amount of active $\mathrm{Fe}_{3} \mathrm{O}_{4}$ and the active copper ferrite $\mathrm{Cu}_{1-x} \mathrm{Fe}_{2+\mathrm{x}} \mathrm{O}_{4}$ [25]. In the compared samples, HRTEM and DD were used to assess the presence of the mixed copper-iron oxide phase and determine the spinel content and its stoichiometry. Figures 8 and 9 show the results of the HRTEM analysis for the little-active CuFe-5 and the active CuFe- 1 . 

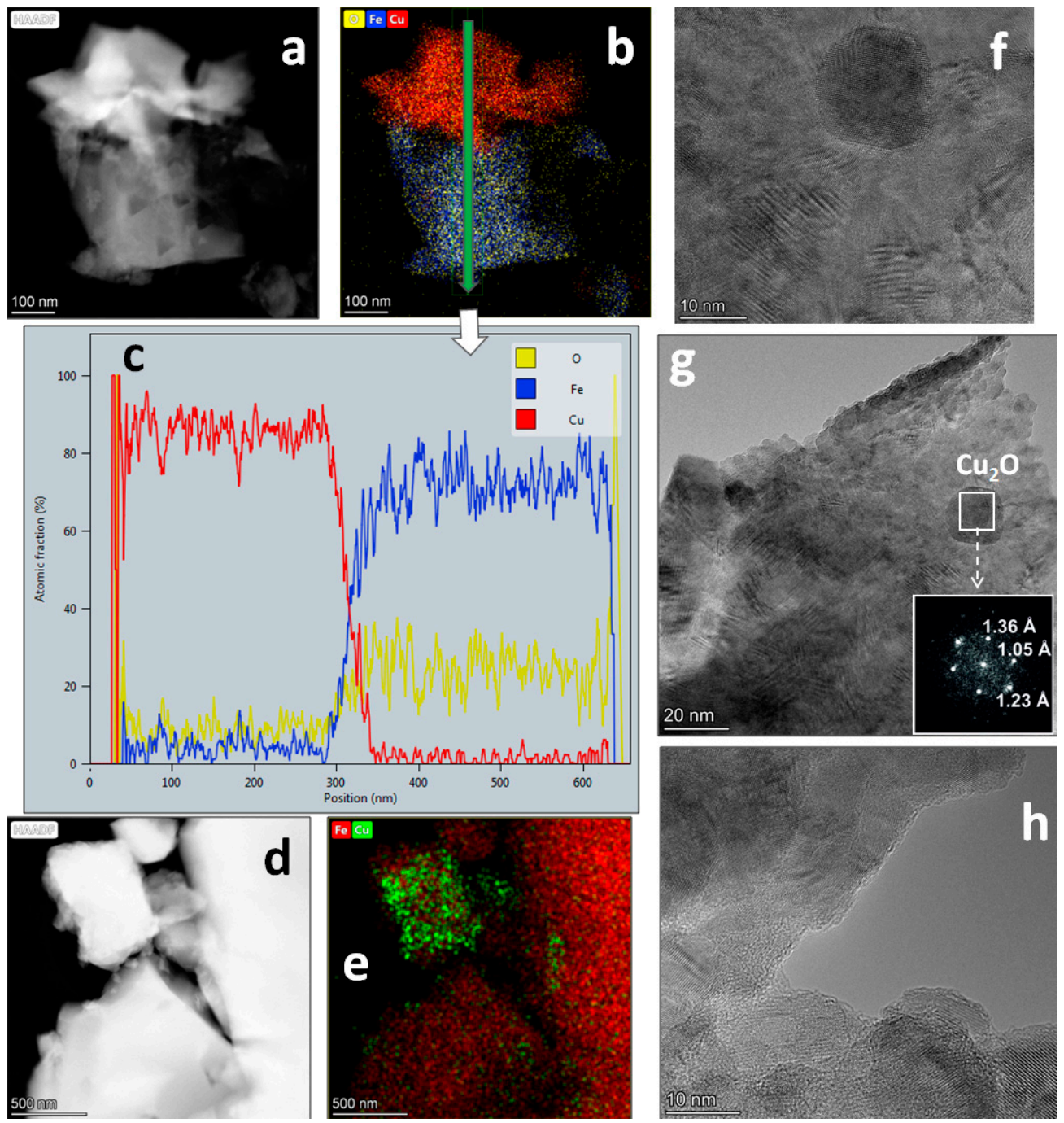

Figure 8. For an inactive $\mathrm{CuFe}-5$ sample before catalytic experiments, (a,d) dark-field images with (b,e) the corresponding elemental mappings, (c) concentrations distribution at a particle scanning shown at (b), (f-h) HRTEM images, and (g) the selected area and its diffraction pattern.

As shown in Figure 8, the particles of the little-active CuFe-5 mainly consist of individual phases of iron and copper. Nanosized spherical particles also occur (Figure 8f,g) and are attributed to $\mathrm{Cu}_{2} \mathrm{O}$ (PDF 5-667). Regions of mixed oxides containing both copper and iron are rare. The concentration of copper in the particles of iron oxide is generally low. It can, therefore, be suggested that, in the CuFe-5 sample, the cubic spinel (34\%) is mainly $\mathrm{Fe}_{3} \mathrm{O}_{4}$ or a slightly $\mathrm{Cu}$-doped $\mathrm{Fe}_{3} \mathrm{O}_{4}$. Additionally, the high-resolution micrographs of this sample indicate the presence of large number of moiré patterns (Figure $8 \mathrm{~g}$ ), which is a consequence of the superposition of periodic layered structures with either slightly different lattice constants or different orientation. Amorphous regions also occur (Figure 8h).

The TEM results for the active CuFe-1 are quite different (Figure 9). All particles of this sample contain both copper and iron, which confirms that the main phase of the cubic spinel $(84 \%)$ is a mixed copper-iron oxide. It is seen that the stoichiometry $\mathrm{Cu} / \mathrm{Fe}$ within a single particle is not constant (Figure $9 d-h$ ). Regions with a higher and a lower content of copper (or iron) occur. We believe that these regions are the sites of localization of individual phases of copper and iron and of the $\mathrm{CuFeO}_{2}$ phase which has a higher $\mathrm{Cu} / \mathrm{Fe}$ ratio than $\mathrm{CuFe}_{2} \mathrm{O}_{4}$. In the HRTEM images, the moiré patterns are practically not observed (Figure $9 \mathrm{i}, \mathrm{j}$ ), which appears to indicate a greater phase homogeneity of this sample. This is consistent with the XRD data (Table 2). 

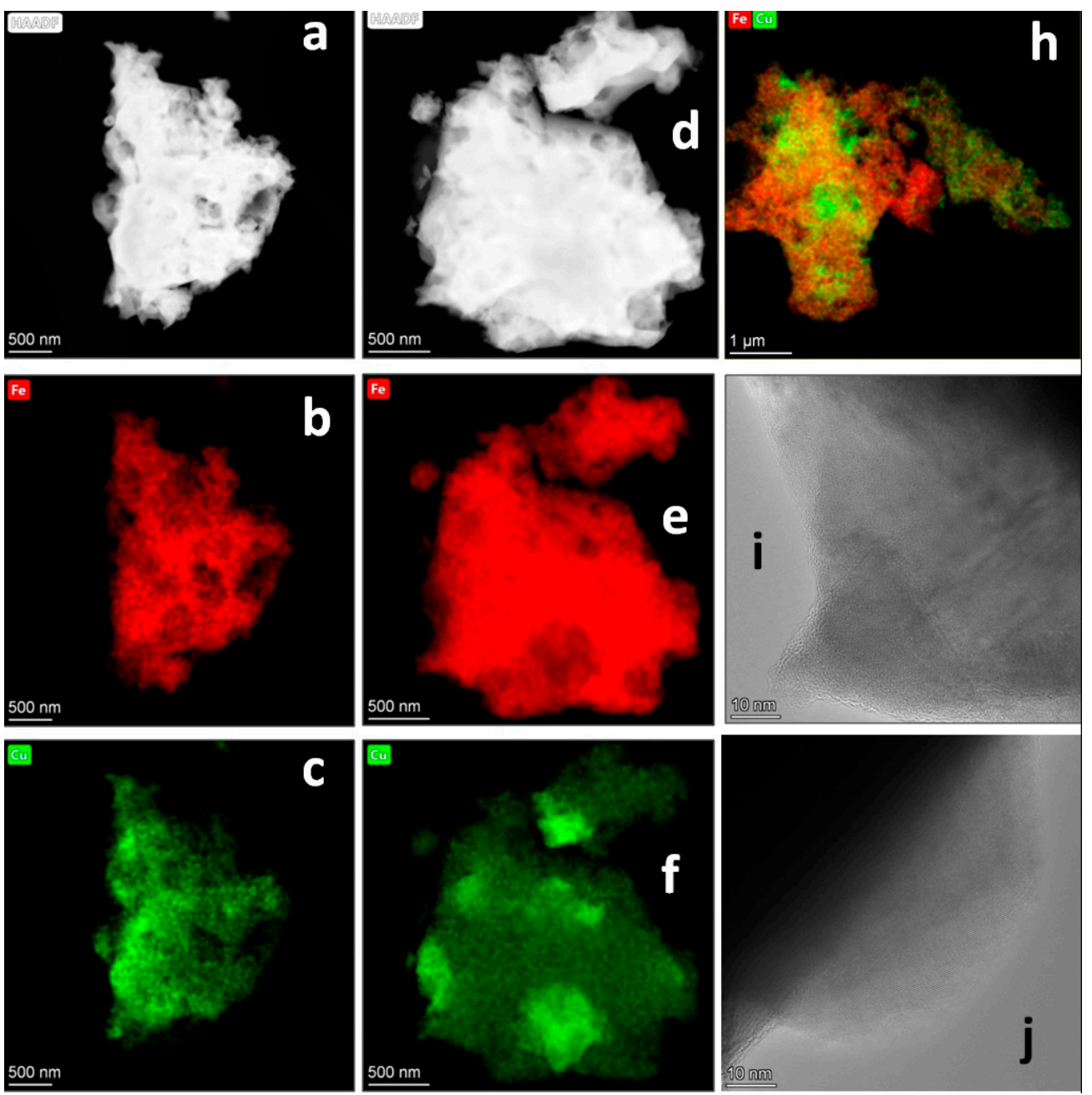

Figure 9. For an active CuFe-1 sample before catalytic experiments, (a,d) dark-field images with (b-f) the corresponding elemental mappings, (h) elemental mappings for another particle, and $(\mathbf{i}, \mathbf{j})$ HRTEM images.

Thus, the comparison of the two products of combustion (CuFe- 1 and $\mathrm{CuFe}-5)$ allows us to conclude that the active $\mathrm{CuFe}-1$ product predominantly consist of more finely dispersed particles of copper ferrite with average stoichiometry of $\mathrm{Cu}_{0.67} \mathrm{Fe}_{2.33} \mathrm{O}_{4}$ and the presence of a number of other phases of copper and iron as an impurity. To answer the question, 'how important are the contents of the cubic spinel, the copper content in the spinel structure and the presence of other compounds of copper and iron for the catalytic activity?', the results of XRD analysis obtained for a number of combustion products prepared under different synthesis conditions (Table 2) have been correlated with their activity in the AB hydrolysis (Figure 6).

The following series were obtained:

- The rate of $\mathrm{H}_{2}$ generation in the presence of CuFe combustion products (Table 2) in the catalytic $\mathrm{AB}$ hydrolysis decreases in the order (Figure 6):

$$
\text { CuFe-1 } \approx \text { CuFe-2 }>\text { CuFe-3 }>\text { CuFe-4 }>\text { CuFe-5; }
$$

- The content of the spinel phase in $\mathrm{w} t \%$ decreases in the order:

$$
\text { CuFe-1 }(84 \%)>\text { CuFe-2 (73\%) > CuFe-3 (66\%) > CuFe-4 (48\%) > CuFe-5 (34\%); }
$$


- $\quad$ CSR of the spinel phase in nm increases in the order:

CuFe-2 $(49 \mathrm{~nm})<\mathrm{CuFe}-3(52 \mathrm{~nm})<\mathrm{CuFe}-1(62 \mathrm{~nm}) \approx \mathrm{CuFe}-4(62 \mathrm{~nm})<\mathrm{CuFe}-5(77 \mathrm{~nm})$;

- The content of the oxide phases of copper $\left(\mathrm{CuO}+\mathrm{Cu}_{2} \mathrm{O}+\mathrm{CuFeO}_{2}\right)$ expressed in $\mathrm{wt} \%$ of $\mathrm{Cu}$ decreases in the order:

$$
\mathrm{CuFe}-2(9.6 \%)>\mathrm{CuFe}-1(7.9 \%) \approx \mathrm{CuFe}-4(7.4 \%) \approx \mathrm{CuFe}-3(7.3 \%)>\mathrm{CuFe}-5(6.2 \%)
$$

- The content of the $\mathrm{CuO}$ phase in $\mathrm{wt} \%$ decreases in the order:

$$
\text { CuFe-2 (12\%) > CuFe-3 (6\%) > CuFe-1 (3\%) > CuFe-4 } \approx \mathrm{CuFe}-5(0 \%) \text {; }
$$

- The content of the $\mathrm{Cu}_{2} \mathrm{O}$ phase in wt $\%$ increases in the order:

$$
\mathrm{CuFe}-1 \approx \mathrm{CuFe}-2 \approx \mathrm{CuFe}-3(0 \%)<\mathrm{CuFe}-4(6 \%) \approx \mathrm{CuFe}-5(7 \%) ;
$$

- The content of the $\mathrm{CuFeO}_{2}$ in $\mathrm{wt} \%$ decreases in the order:

$$
\mathrm{CuFe}-1(13 \%)>\mathrm{CuFe}-3(6 \%) \approx \mathrm{CuFe}-4(5 \%)>\mathrm{CuFe}-2 \approx \mathrm{CuFe}-5(0 \%)
$$

- The content of the $\mathrm{Cu}^{0}$ phase $(\mathrm{CSR}>150 \mathrm{~nm})$ in $\mathrm{wt} \%$ increases in the order:

$$
\text { CuFe-1 }(0 \%)<\text { CuFe-2 }(6 \%)<\mathrm{CuFe}-3(14 \%) \approx \mathrm{CuFe}-4(15 \%)<\mathrm{CuFe}-5(18 \%) \text {; }
$$

- The content of all impurity phases of copper (all of the oxide phases of copper $+\mathrm{Cu}^{0}$ ) expressed in $\mathrm{wt}_{\mathrm{t}} \%$ of $\mathrm{Cu}$ increases in the order:

$$
\text { CuFe-1 }(7.9 \%)<\text { CuFe-2 }(15.6 \%)<\text { CuFe-3 }(21.3 \%) \approx \mathrm{CuFe}-4(22.4 \%)<\mathrm{CuFe}-5(24.2 \%) \text {; }
$$

- The content of the $\mathrm{Fe}_{2} \mathrm{O}_{3}$ phase in $\mathrm{wt} \%$ increases in the order:

$$
\text { CuFe-1 }(0 \%)<\mathrm{CuFe}-3(8 \%) \approx \mathrm{CuFe}-2(9 \%)<\mathrm{CuFe}-4(26 \%)<\mathrm{CuFe}-5(40 \%) .
$$

The comparison of these results allows us to obtain more detailed information concerning the composition of the active catalyst. Note that activity is not explained by the dispersity (CSR, $\left.\mathrm{S}_{\mathrm{BET}}\right)$ of these samples. It was shown that the activity of the studied combustion products (4) correlates with their content of the cubic spinel (5). The higher the content of the cubic spinel, the higher the activity. The activity of the studied combustion products tends to decrease with the increasing fraction of the impurity phases of copper $\left(\mathrm{CuO}+\mathrm{Cu}_{2} \mathrm{O}+\mathrm{CuFeO}_{2}+\mathrm{Cu}^{0}\right)(12)$ and the increasing content of the inactive phase $\mathrm{Fe}_{2} \mathrm{O}_{3}$ (13). This explains the high activity of $\mathrm{CuFe}-1$, which mainly consists of the cubic spinel $(83 \%)$ with a relatively large extent of the $\mathrm{Fe}^{2+}$ substitution by $\mathrm{Cu}^{2+}(\mathrm{Cu} / \mathrm{Fe}=0.29$ in moles $)$.

On the other hand, from the results of the present study, it follows that the high content of copper in the lattice of the cubic spinel is not an indispensable condition for a high catalytic activity. In contrast to $\mathrm{CuFe}-1$, the spinels of the other products are characterized by rather low theoretical molar ratios $\mathrm{Cu} / \mathrm{Fe}<0.1$, since a considerable portion of copper in these samples is present in the form of individual compounds (Table 2). This is especially characteristic of CuFe-2 sample, whose activity in the AB hydrolysis (Figure 6) is comparable to that of CuFe-1 at an XRD derived content of the cubic spinel of $73 \%$. A DD analysis of this sample (Table 3) confirmed the XRD results and allowed us to obtain more exact values of the $\mathrm{Cu} / \mathrm{Fe}$ molar ratio in the spinel of this sample. It was found to be 0.06 which corresponds to the $\mathrm{Cu}_{0.16} \mathrm{Fe}_{2.84} \mathrm{O}_{4}$ composition. 
Table 3. The comparison the phase composition of CuFe-1 and CuFe-2 according to the results of $\mathrm{X}$-ray diffraction method (XRD) and differential dissolution (DD).

\begin{tabular}{ccc}
\hline Sample & XRD (wt\%) & DD (wt\%) \\
\hline & $84 \% \mathrm{Cu}_{1-\mathrm{x}} \mathrm{Fe}_{2+\mathrm{x}} \mathrm{O}_{4}(\mathrm{cub}$. & $75.9 \% \mathrm{Cu}_{0.29} \mathrm{Fe}_{1}{ }^{1}$ \\
CuFe-1 & spinel) & $14.4 \% \mathrm{Cu}_{1}$ \\
& $13 \% \mathrm{CuFeO} 2$ & $9.7 \% \mathrm{Fe}_{1}$ \\
& $3 \% \mathrm{CuO}$ & \\
\hline $\mathrm{CuFe}-2$ & $73 \%$ spinel & $66.7 \% \mathrm{Cu}_{0.06} \mathrm{Fe}_{1}{ }^{2}$ \\
& $6 \% \mathrm{Cu}$ & $29.3 \% \mathrm{Cu}_{1}$ \\
& $12 \% \mathrm{CuO}$ & $4.0 \% \mathrm{Fe}_{1}$ \\
\hline
\end{tabular}

${ }^{1}$ Corresponds to $\mathrm{Cu}_{0.67} \mathrm{Fe}_{2.33} \mathrm{O}_{4}$ formula. ${ }^{2}$ Corresponds to $\mathrm{Cu}_{0.16} \mathrm{Fe}_{2.84} \mathrm{O}_{4}$ formula.

Further correlation between the order of activities of CuFe-samples (4) and their contents of $\mathrm{CuO}(8), \mathrm{Cu}_{2} \mathrm{O}(9), \mathrm{CuFeO}_{2}(10)$, and $\mathrm{Cu}^{0}$ (11) phases allowed us to make the following conclusions. The active samples $\mathrm{CuFe}-1, \mathrm{CuFe}-2$ and $\mathrm{CuFe}-3$ do not contain $\mathrm{Cu}_{2} \mathrm{O}$. The high activity cannot also be related to the presence of coarsely dispersed metallic copper. On the contrary, it is the low-active samples CuFe- 4 and CuFe- 5 that contain a considerable amount of reduced copper (15-18 wt\%) (11), a high content of $\mathrm{Fe}_{2} \mathrm{O}_{3}$ (13), a low content of the spinel (5) and a $\mathrm{Cu}_{2} \mathrm{O}$ impurity (9). According to $\mathrm{XRD}$, the value of $\mathrm{CSR}$ of $\mathrm{Cu}^{0}$ formed upon the combustion is $>150 \mathrm{~nm}$ (Table 2), which substantially exceeds the CSR of the active copper forming from the oxides in the reaction medium of ammonia borane $(\leq 40 \mathrm{~nm})$ [25]; this seems to be responsible for the low activity of such samples. There is no correlation between the activity and the presence of the $\mathrm{CuFeO}_{2}$ phase. For example, this phase is not present in the active CuFe-2 but is found in the low-activity $\mathrm{CuFe}-4$ and in the active CuFe-1.

In our opinion, the high activity of $\mathrm{CuFe}-2$ comparable to that of $\mathrm{CuFe}-1$ may be related to its high content of $\mathrm{CuO}(12 \%)$ (Table 2, (8)). The $\mathrm{CuO}$ phase is also found in the most active sample CuFe-1 (3\%) and in the sample CuFe-3 (6\%)-the next member in the order of activities. The least active samples $\mathrm{CuFe}-4$ and $\mathrm{CuFe}-5$ do not contain $\mathrm{CuO}$.

This allowed us to suggest that the active combustion product may not only show a relatively high extent of $\mathrm{Fe}^{2+}$ substitution by $\mathrm{Cu}^{2+}$ in spinel structure but also it may predominantly consist of $\mathrm{Fe}_{3} \mathrm{O}_{4}$ (including with the presence in its structure of a small content of copper) together with an amount of the active $\mathrm{CuO}$ phase. We believe that as in the case of mixed $\mathrm{Cu}-\mathrm{Fe}$ oxide phase, the reduction of $\mathrm{CuO}$ at the $\mathrm{CuO}-\mathrm{Fe}_{3} \mathrm{O}_{4}$ interface to form active $\mathrm{Cu}-\mathrm{H}$ sites must lead to the reduction of iron in the structure of $\mathrm{Fe}_{3} \mathrm{O}_{4}$. A similar effect has been described for the systems $\mathrm{CuO} / \mathrm{Co}_{3} \mathrm{O}_{4}$ [38] and $\mathrm{CuO}-\mathrm{NiO} / \mathrm{Co}_{3} \mathrm{O}_{4}$ [39], which are being investigated for use in $\mathrm{AB}$ hydrolysis. No such evidence has been reported for $\mathrm{Fe}_{3} \mathrm{O}_{4}$. It should be noted that the potential of active iron-containing components in the catalytic processes discussed in this study is still little studied. However, there have been some reported results dealing with the promoting action of iron on active nickel and cobalt-active components $[8,10,57-60]$.

To verify this assumption, in an experiment an amount of $\mathrm{Fe}_{3} \mathrm{O}_{4}$ was ground with a basic carbonate of copper and the mixture was calcined in air at $300^{\circ} \mathrm{C}$ for $4 \mathrm{~h}$ to produce a $10 \mathrm{wt} \% \mathrm{CuO} / \mathrm{Fe}_{3} \mathrm{O}_{4}$. We were aware that this method of preparation is not the most optimal and efficient, since a mere calcination of such a mixture cannot ensure the formation of the active nano-dispersed states of $\mathrm{CuO}$ and, in addition, there a partial oxidation of $\mathrm{Fe}_{3} \mathrm{O}_{4}$ to $\gamma-\mathrm{Fe}_{2} \mathrm{O}_{3}$ will take place; the latter is less active than $\mathrm{Fe}_{3} \mathrm{O}_{4}$ [25]. However, it was a fast way to verify our assumptions. Indeed, the data in Figure 10 show that $\mathrm{Fe}_{3} \mathrm{O}_{4}$ modification by a small amount of $\mathrm{CuO}$ facilitates a considerable increase in its activity. The observed activity of $10 \mathrm{wt} \% \mathrm{CuO} / \mathrm{Fe}_{3} \mathrm{O}_{4}$ exceeds that of the analogously prepared bulk $\mathrm{CuO}$. These results may help to find new approaches to the creation of novel $\mathrm{Fe}_{3} \mathrm{O}_{4}$-based active materials for water-employed $\mathrm{AB}$ dehydrogenation. 


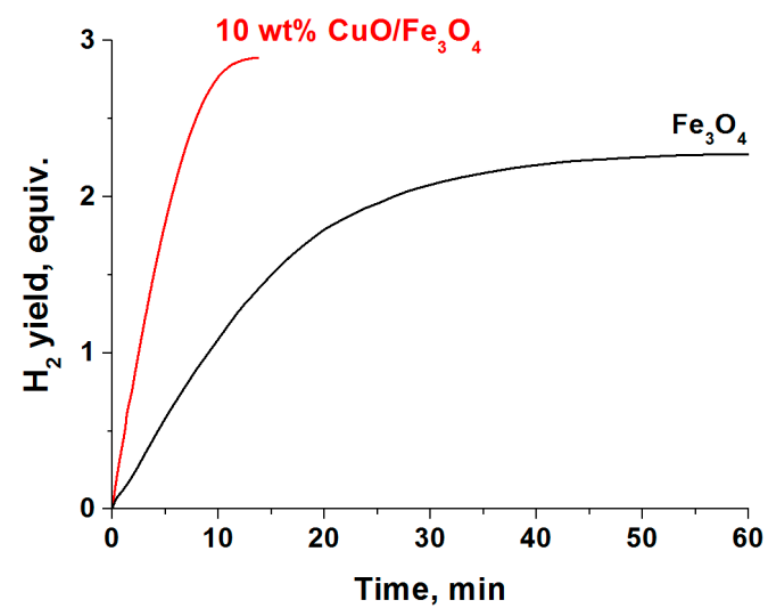

Figure 10. The change of activity of $\mathrm{Fe}_{3} \mathrm{O}_{4}$ in the catalytic hydrolysis of $\mathrm{NH}_{3} \mathrm{BH}_{3}(0.123 \mathrm{M})$ at $60{ }^{\circ} \mathrm{C}$ upon its modification by $\mathrm{CuO}(10 \mathrm{wt} \%)$.

\section{Conclusions}

The catalytic activity of $\mathrm{Fe}_{3} \mathrm{O}_{4}$ in the reactions of ammonia borane hydrolysis and hydrothermolysis has been compared with the activity of copper and cobalt ferrites with the structure of a cubic spinel prepared by combustion of glycine-nitrate precursors. In the process of $A B$ hydrothermolysis, a highly exothermic reaction of $A B$ hydrolysis is coupled with the subsequent stage of $A B$ thermolysis. Note that, with this process, high values of GHD $(>7 \mathrm{wt} \%)$ can be achieved at relatively low temperatures of the external heating $\left(>80^{\circ} \mathrm{C}\right)[20,21,23-25]$.

The rate of hydrogen generation was found to change in the order

$\mathrm{Cu}_{0.67} \mathrm{Fe}_{2.33} \mathrm{O}_{4}>\mathrm{Co}_{0.90} \mathrm{Fe}_{2.10} \mathrm{O}_{4}>\mathrm{Co}_{3} \mathrm{O}_{4}>\mathrm{CuO}>\mathrm{Fe}_{3} \mathrm{O}_{4}$. This order was not explained by the dispersity of studied samples, but depended on their chemical composition. The obtained results indicated a synergic action of the metals comprising the spinel. The advantages of using copper ferrite are not only its high activity in the AB hydrolysis and hydrothermolysis, but also the absence of an induction period in the curves of hydrogen generation which is associated with its fast reduction in the reaction medium to form active nanodispersed $\mathrm{Fe}^{0}$ and $\mathrm{Cu}^{0}$ [25]. A comparison of the results for the activity of copper and cobalt ferrites in reaction media having different reducing powers (solutions of $\mathrm{NH}_{3} \mathrm{BH}_{3}$, $\mathrm{NH}_{3} \mathrm{BH}_{3}+\mathrm{NaBH}_{4}$ and $\mathrm{NaBH}_{4}$ ) confirmed the easier reduction of the copper-containing oxide. It has been suggested [10] that this happens because of the easier reduction of copper in the hydride medium to produce hydridic $\mathrm{Cu}-\mathrm{H}$ species accelerating reduction of other metals in the oxide structure. The activating action of the compounds of copper, including its oxides, is well known and has been employed in the processes of hydrogenation of different organic substrates where ammonia borane is used as a mild reducer [61-63].

The obtained results allow us to suggest that the formation of the active hydridic $\mathrm{Cu}-\mathrm{H}$ species is of importance not only for the initial stage of activation, but also for the later stage of the active generation of hydrogen, preventing the oxidation of the active, nanosized component in the aqueous medium.

To reveal the most significant parameters of the active catalytic system on the basis of copper-containing spinel, the activity of a series of combustion products which differed in the their dispersity has been analyzed: the contents of the cubic spinel, the content of copper in spinel structure and the content and composition of impurity phases. Based on the obtained results, it was suggested that the catalyst may be active not only when a portion of $\mathrm{Fe}^{2+}$ in cubic spinel structure is replaced by $\mathrm{Cu}^{2+}$, but also when it consists of $\mathrm{Fe}_{3} \mathrm{O}_{4}$ with an amount of $\mathrm{CuO}$.

Thus, the obtained results show the high potential of the copper-modified $\mathrm{Fe}_{3} \mathrm{O}_{4}$ as a precursor, allowing the active catalytic states to be formed directly in the reaction medium. We believe that such catalytic systems may be improved further by replacing a portion of 
$\mathrm{Fe}^{2+}$ cations in the spinel structure by active cations $\left(\mathrm{Ni}^{2+}, \mathrm{Co}^{2+}\right.$, etc.) together with $\mathrm{Cu}^{2+}$ or by preparation of finely dispersed multi-phase oxide systems, involving oxide of copper.

Supplementary Materials: The following are available online at https://www.mdpi.com/article/10 .3390/ma14185422/s1: Section: the preparation procedures of combustion products; Figure S1: the combustion synthesis of $\mathrm{CuFe}-1$ and $\mathrm{CuFe}-5$ samples as the process went on in time; Figure S2: the combustion synthesis of $\mathrm{CuFe}-2, \mathrm{CuFe}-3$ and $\mathrm{CuFe}-4$ samples as the process went on in time; Figure S3: the combustion synthesis of CoFe sample as the process went on in time; Figure S4: typical kinetic curves of concentration of measured elements and changes of temperature and acidity of solvent on the time of sample dissolution in flow regime of DD experiment; Figure S5: kinetic curves of concentration of cobalt and iron and calculated $\mathrm{Co} / \mathrm{Fe}$ molar ratio on the time of dissolution of $\mathrm{CoFe}$ sample; Figure S6: dynamics of dissolution of isolated phase of copper ferrite $\left(\mathrm{Co}_{0.90} \mathrm{Fe}_{2.10} \mathrm{O}_{4}\right)$ and remaining phases of cobalt (oxide, metal) and iron (presumably $\mathrm{Fe}_{2} \mathrm{O}_{3}$ ); Figure S7: (a) kinetic curves of concentration of copper and iron and calculated $\mathrm{Cu} / \mathrm{Fe}$ molar ratio, (b) dynamics of dissolution of isolated phase of copper ferrite $\left(\mathrm{Cu}_{0.67} \mathrm{Fe}_{2.33} \mathrm{O}_{4}\right)$ and remaining phases of cupper (oxides, metal) and iron (presumably $\mathrm{Fe}_{2} \mathrm{O}_{3}$ ) during dissolution of CuFe-1 sample; Figure S8: (a) kinetic curves of concentration of copper and iron and calculated $\mathrm{Cu} / \mathrm{Fe}$ molar ratio, (b) dynamics of dissolution of isolated phase of copper ferrite $\left(\mathrm{Cu}_{0.16} \mathrm{Fe}_{2.84} \mathrm{O}_{4}\right)$ and remaining phases of copper (oxides, metal) and iron (presumably $\mathrm{Fe}_{2} \mathrm{O}_{3}$ ) during dissolution of CuFe-2 sample; Figure S9: SEM images for CuFe-1, $\mathrm{CuFe}-3$ иСuFe-5 combustion products (Table 2).

Author Contributions: Writing-review and editing, O.V.K.; conceptualization, V.I.S. and O.V.K.; methodology, V.I.S.; data curation, A.M.O. and E.S.T.; investigation, A.A.P., O.A.B., A.V.I., G.V.O., A.M.G., I.L.L., and S.A.M.; visualization, E.S.T. and A.V.I.; formal analysis, S.A.M. and I.L.L.; validation, A.A.P., O.A.B. and G.V.O.; writing-original draft preparation, A.M.O., A.M.G. and O.V.N.; project administration, O.V.N. All authors have read and agreed to the published version of the manuscript.

Funding: This work was supported by the Ministry of Science and Higher Education of the Russian Federation within the governmental order for Boreskov Institute of Catalysis, project AAAA-A21121011390006-0.

Acknowledgments: Authors are very gratefully to N.A. Rudina for the study the samples by the scanning electron microscope (SEM).

Conflicts of Interest: The authors declare no conflict of interest.

\section{References}

1. Staubitz, A.; Robertson, A.P.M.; Manners, I. Ammonia-Borane and related compounds as dihydrogen sources. Chem. Rev. 2010, 110, 4079-4124. [CrossRef]

2. Peng, B.; Chen, J. Ammonia borane as an efficient and lightweight hydrogen storage medium. Energy. Environ. Sci. 2008, 1, 479-483. [CrossRef]

3. Li, H.; Yang, Q.; Chen, X.; Shore, S.G. Ammonia borane, past as prolog. J. Organomet. Chem. 2014, 751, 60-66. [CrossRef]

4. Demirci, U.B. Ammonia borane, a material with exceptional properties for chemical hydrogen storage. Int. J. Hydrogen. Energy. 2017, 42, 9978-10013. [CrossRef]

5. Demirci, U.B. Ammonia borane: An extensively studied, though not yet implemented, hydrogen carrier. Energies 2020, $13,3071$. [CrossRef]

6. Huang, Z.; Autrey, T. Boron-nitrogen-hydrogen (BNH) compounds: Recent developments in hydrogen storage, applications in hydrogenation and catalysis, and new syntheses. Energy. Environ. Sci. 2012, 5, 9257-9268. [CrossRef]

7. Kumar, R.; Karkamkar, A.; Bowden, M.; Autrey, T. Solid-state hydrogen rich boron-nitrogen compounds for energy storage. Chem. Soc. Rev. 2019, 48, 5350-5380. [CrossRef]

8. Yüksel Alpaydın, C.; Gülbay, S.K.; Ozgur Colpan, C. A review on the catalysts used for hydrogen production from ammonia borane. Int. J. Hydrogen. Energy. 2020, 45, 3414-3434. [CrossRef]

9. Wu, H.; Cheng, Y.; Fan, Y.; Lu, X.; Li, L.; Liu, B.; Li, B.; Lu, S. Metal-catalyzed hydrolysis of ammonia borane: Mechanism, catalysts, and challenges. Int. J. Hydrogen. Energy 2020, 45, 30325-30340. [CrossRef]

10. Wang, C.; Zhao, J.; Du, X.; Sun, S.; Yu, X.; Zhang, X.; Lu, Z.; Li, L.; Yang, X. Hydrogen production from ammonia borane hydrolysis catalyzed by non-noble metal-based materials: A review. J. Mater. Sci. 2021, 56, 2856-2878. [CrossRef]

11. Jeong, J.; Bhosale, V.K.; Kwon, S. Ultrafast igniting, low toxicity hypergolic hybrid solid fuels and hydrogen peroxide oxidizer. Fuel 2021, 286, 119307. [CrossRef] 
12. Gong, A.; Verstraete, D. Fuel cell propulsion in small fixed-wing unmanned aerial vehicles: Current status and research needs. Int. J. Hydrogen. Energy. 2017, 42, 21311-21333. [CrossRef]

13. Faverio, C.; Boselli, M.F.; Medici, F.; Benaglia, M. Ammonia borane as a reducing agent in organic synthesis. Org. Biomol. Chem. 2020, 18, 7789-7813. [CrossRef]

14. Kalidindi, S.B.; Sanyal, U.; Jagirdar, B.R. Chemical synthesis of metal nanoparticles using amine-boranes. Chem. Sus. Chem. 2011, 4, 317-324. [CrossRef] [PubMed]

15. Jiang, H.L.; Akita, T.; Xu, Q. A one-pot protocol for synthesis of non-noble metal-based core-shell nanoparticles under ambient conditions: Toward highly active and cost-effective catalysts for hydrolytic dehydrogenation of $\mathrm{NH}_{3} \mathrm{BH}_{3}$. Chem. Commun. 2011, 47, 10999-11001. [CrossRef]

16. Kostka, J.F.; Schellenberg, R.; Baitalow, F.; Smolinka, T.; Mertens, F. Concentration-dependent dehydrogenation of ammoniaborane/triglyme mixtures. Eur. J. Inorg. Chem. 2012, 2012, 49-54. [CrossRef]

17. Sonnenberg, J.F.; Morris, R.H. Evidence for iron nanoparticles catalyzing the rapid dehydrogenation of ammonia-borane. ACS. Catal. 2013, 3, 1092-1102. [CrossRef]

18. Yao, Q.; DIng, Y.; Lu, Z.H. Noble-metal-free nanocatalysts for hydrogen generation from boron- and nitrogen-based hydrides. Inorg. Chem. Front. 2020, 7, 3837-3874. [CrossRef]

19. Li, J.; Ren, X.; Lv, H.; Wang, Y.; Li, Y.; Liu, B. Highly efficient hydrogen production from hydrolysis of ammonia borane over nanostructured $\mathrm{Cu} @ \mathrm{CuCoO}_{\mathrm{x}}$ supported on graphene oxide. J. Hazard. Mater. 2020, 391, 122199. [CrossRef]

20. Diwan, M.; Hwang, H.T.; Al-Kukhun, A.; Varma, A. Hydrogen generation from noncatalytic hydrothermolysis of ammonia borane for vehicle applications. AIChE J. 2011, 57, 259-264. [CrossRef]

21. Hwang, H.T.; Al-Kukhun, A.; Varma, A. Hydrogen for vehicle applications from hydrothermolysis of ammonia borane: Hydrogen yield, thermal characteristics, and ammonia formation. Ind. Eng. Chem. Res. 2010, 49, 10994-11000. [CrossRef]

22. Zhang, J.; Zhao, Y.; Akins, D.L.; Lee, J.W. Calorimetric and microscopic studies on the noncatalytic hydrothermolysis of ammonia borane. Ind. Eng. Chem. Res. 2011, 50, 10407-10413. [CrossRef]

23. Komova, O.V.; Kayl, N.L.; Odegova, G.V.; Netskina, O.V.; Simagina, V.I. Destabilization of $\mathrm{NH}_{3} \mathrm{BH}_{3}$ by water during hydrothermolysis as a key factor in the high hydrogen evolution rates. Int. J. Hydrogen. Energy. 2016, 41, 17484-17495. [CrossRef]

24. Gorlova, A.M.; Kayl, N.L.; Komova, O.V.; Netskina, O.V.; Ozerova, A.M.; Odegova, G.V.; Bulavchenko, O.A.; Ishchenko, A.V.; Simagina, V.I. Fast hydrogen generation from solid $\mathrm{NH}_{3} \mathrm{BH}_{3}$ under moderate heating and supplying a limited quantity of CoCl 2 or $\mathrm{NiCl}_{2}$ solution. Renew. Energy. 2018, 121, 722-729. [CrossRef]

25. Komova, O.V.; Odegova, G.V.; Gorlova, A.M.; Bulavchenko, O.A.; Pochtar, A.A.; Netskina, O.V.; Simagina, V.I. Copper-iron mixed oxide catalyst precursors prepared by glycine-nitrate combustion method for ammonia borane dehydrogenation processes. Int. J. Hydrogen. Energy. 2019, 44, 24277-24291. [CrossRef]

26. Kalidindi, S.B.; Sanyal, U.; Jagirdar, B.R. Nanostructured $\mathrm{Cu}$ and $\mathrm{Cu} @ \mathrm{Cu}_{2} \mathrm{O}$ core shell catalysts for hydrogen generation from ammonia-borane. Phys. Chem. Chem. Phys. 2008, 10, 5870-5874. [CrossRef]

27. Yan, J.M.; Zhang, X.B.; Han, S.; Shioyama, H.; Xu, Q. Iron-nanoparticle-catalyzed hydrolytic dehydrogenation of ammonia borane for chemical hydrogen storage. Angew. Chemie Int. Ed. 2008, 47, 2287-2289. [CrossRef]

28. Cavaliere, S.; Hannauer, J.; Demirci, U.B.; Akdim, O.; Miele, P. Ex situ characterization of $\mathrm{N}_{2} \mathrm{H}_{4}-, \mathrm{NaBH}_{4}-$ and $\mathrm{NH}_{3} \mathrm{BH}_{3}-\mathrm{reduced}$ cobalt catalysts used in $\mathrm{NaBH}_{4}$ hydrolysis. Catal. Today. 2011, 170, 3-12. [CrossRef]

29. Simagina, V.I.; Komova, O.V.; Ozerova, A.M.; Netskina, O.V.; Odegova, G.V.; Kellerman, D.G.; Bulavchenko, O.A.; Ishchenko, A.V. Cobalt oxide catalyst for hydrolysis of sodium borohydride and ammonia borane. Appl. Catal. A. Gen. 2011, 394, 86-92. [CrossRef]

30. Yang, Y.W.; Lu, Z.H.; Chen, X.S. Cu-based nanocatalysts for hydrogen generation via hydrolysis and methanolysis of ammonia borane. Mater. Technol. 2015, 30, A89-A93. [CrossRef]

31. Liu, Q.; Zhang, S.; Liao, J.; Feng, K.; Zheng, Y.; Pollet, B.G.; Li, H. $\mathrm{CuCo}_{2} \mathrm{O}_{4}$ nanoplate film as a low-cost, highly active and durable catalyst towards the hydrolytic dehydrogenation of ammonia borane for hydrogen production. J. Power. Sources. 2017, 355, 191-198. [CrossRef]

32. Liao, J.; Feng, Y.; Wu, S.; Ye, H.; Zhang, J.; Zhang, X.; Xie, F.; Li, H. Hexagonal $\mathrm{CuCo}_{2} \mathrm{O}_{4}$ nanoplatelets, a highly active catalyst for the hydrolysis of ammonia borane for hydrogen production. Nanomaterials 2019, 9, 360. [CrossRef] [PubMed]

33. Lu, D.; Liao, J.; Zhong, S.; Leng, Y.; Ji, S.; Wang, H.; Wang, R.; Li, H. $\mathrm{Cu}_{0.6} \mathrm{Ni}_{0.4} \mathrm{Co}_{2} \mathrm{O}_{4}$ nanowires, a novel noble-metal-free catalyst with ultrahigh catalytic activity towards the hydrolysis of ammonia borane for hydrogen production. Int. J. Hydrogen. Energy. 2018, 43, 5541-5550. [CrossRef]

34. Lu, D.; Li, J.; Lin, C.; Liao, J.; Feng, Y.; Ding, Z.; Li, Z.; Liu, Q.; Li, H. A simple and scalable route to synthesize $\mathrm{Co}_{\mathrm{x}} \mathrm{Cu}_{1-\mathrm{x}} \mathrm{Co}_{2} \mathrm{O}_{4} @ \mathrm{Co}_{\mathrm{y}} \mathrm{Cu}_{1-\mathrm{y}} \mathrm{Co}_{2} \mathrm{O}_{4}$ yolk-shell microspheres, a high-performance catalyst to hydrolyze ammonia borane for hydrogen production. Small 2019, 15, 1805460. [CrossRef] [PubMed]

35. Lu, D.; Liao, J.; Leng, Y.; Zhong, S.; He, J.; Wang, H.; Wang, R.; Li, H. Mo-doped $\mathrm{Cu}_{0.5} \mathrm{Ni}_{0.5} \mathrm{Co}_{2} \mathrm{O}_{4}$ nanowires, a strong substitute for noble-metal-based catalysts towards the hydrolysis of ammonia borane for hydrogen production. Catal. Commun. 2018, 114, 89-92. [CrossRef]

36. Liao, J.; Lu, D.; Diao, G.; Zhang, X.; Zhao, M.; Li, H. $\mathrm{Co}_{0.8} \mathrm{Cu}_{0.2} \mathrm{MoO}_{4}$ microspheres composed of nanoplatelets as a robust catalyst for the hydrolysis of ammonia borane. ACS Sustain. Chem. Eng. 2018, 6, 5843-5851. [CrossRef] 
37. Lu, D.; Liao, J.; Li, H.; Ji, S.; Pollet, B.G. $\mathrm{Co}_{3} \mathrm{O}_{4} / \mathrm{CuMoO}_{4}$ hybrid microflowers composed of nanorods with rich particle boundaries as a highly active catalyst for ammonia borane hydrolysis. ACS Sustain. Chem. Eng. 2019, 7, 16474-16482. [CrossRef]

38. Yamada, Y.; Yano, K.; Xu, Q.; Fukuzumi, S. Cu/ $\mathrm{Co}_{3} \mathrm{O}_{4}$ nanoparticles as catalysts for hydrogen evolution from ammonia borane by hydrolysis. J. Phys. Chem. C 2010, 114, 16456-16462. [CrossRef]

39. Liao, J.; Feng, Y.; Lin, W.; Su, X.; Ji, S.; Li, L.; Zhang, W.; Pollet, B.G.; Li, H. CuO-NiO/ $\mathrm{Co}_{3} \mathrm{O}_{4}$ hybrid nanoplates as highly active catalyst for ammonia borane hydrolysis. Int. J. Hydrogen Energy 2020, 45, 8168-8176. [CrossRef]

40. Özkar, S. Magnetically separable transition metal nanoparticles as catalysts in hydrogen generation from the hydrolysis of ammonia borane. Int. J. Hydrogen. Energy. 2021, 46, 21383-21400. [CrossRef]

41. Kaya, M.; Zahmakiran, M.; Özkar, S.; Volkan, M. Copper(0) nanoparticles supported on silica-coated cobalt ferrite magnetic particles: Cost effective catalyst in the hydrolysis of ammonia-borane with an exceptional reusability performance. ACS Appl. Mater. Interfaces. 2012, 4, 3866-3873. [CrossRef]

42. Liang, Z.; Li, Q.; Li, F.; Zhao, S.; Xia, X. Hydrogen generation from hydrolysis of $\mathrm{NaBH}_{4}$ based on high stable $\mathrm{NiB} / \mathrm{NiFe}{ }_{2} \mathrm{O}_{4}$ catalyst. Int. J. Hydrogen. Energy. 2017, 42, 3971-3980. [CrossRef]

43. Manna, J.; Akbayrak, S.; Özkar, S. Nickel(0) nanoparticles supported on bare or coated cobalt ferrite as highly active, magnetically isolable and reusable catalyst for hydrolytic dehydrogenation of ammonia borane. J. Colloid. Interface. Sci. 2017, 508, 359-368. [CrossRef] [PubMed]

44. Manna, J.; Akbayrak, S.; Özkar, S. Palladium(0) nanoparticles supported on polydopamine coated $\mathrm{CoFe}_{2} \mathrm{O}_{4}$ as highly active, magnetically isolable and reusable catalyst for hydrogen generation from the hydrolysis of ammonia borane. Appl. Catal. $B$ Environ. 2017, 208, 104-115. [CrossRef]

45. Abd El-Hafiz, D.R.; Eshaq, G.; ElMetwally, A.E. Recent enhancement of ammonia borane hydrolysis using spinel-type metal ferrites nano-catalysts. Mater. Chem. Phys. 2018, 217, 562-569. [CrossRef]

46. Tang, M.; Xia, F.; Gao, C.; Qiu, H. Preparation of magnetically recyclable $\mathrm{CuFe}_{2} \mathrm{O}_{4} / \mathrm{RGO}_{\text {for }}$ catalytic hydrolysis of sodium borohydride. Int. J. Hydrogen. Energy. 2016, 41, 13058-13068. [CrossRef]

47. Simagina, V.I.; Komova, O.V.; Odegova, G.V.; Netskina, O.V.; Bulavchenko, O.A.; Pochtar', A.A.; Kayl, N.L. Study of copper-iron mixed oxide with cubic spinel structure, synthesized by the combustion method. Russ. J. Appl. Chem. 2019, 92, 20-30. [CrossRef]

48. Malakhov, V.V.; Vasilyeva, I.G. Stoichiography and chemical methods of phase analysis of multielement multiphase compounds and materials. Russ. Chem. Rev. 2008, 77, 370-392. [CrossRef]

49. Pochtar', A.A.; Malakhov, V.V. New stoichiographic methods for assessing spatial inhomogeneities in the composition and structure of solid substances and materials. Inorg. Mater. 2018, 54, 749-755. [CrossRef]

50. Silva, M.D.P.; Silva, F.C.; Sinfrônio, F.S.M.; Paschoal, A.R.; Silva, E.N.; Paschoal, C.W.A. The effect of cobalt substitution in crystal structure and vibrational modes of $\mathrm{CuFe}_{2} \mathrm{O}_{4}$ powders obtained by polymeric precursor method. J. Alloys Compd. 2014, 584, 573-580. [CrossRef]

51. Ishii, M.; Nakahira, M.; Yamanaka, T. Infrared absorption spectra and cation distributions in (Mn, Fe) $\mathrm{O}_{4}$. Solid. State. Commun 1972, 11, 209-212. [CrossRef]

52. Ristić, M.; Hannoyer, B.; Popović, S.; Musić, S.; Bajraktaraj, N. Ferritization of copper ions in the Cu-Fe-O system. Mater. Sci. Eng. B Solid-State Mater. Adv. Technol. 2000, 77, 73-82. [CrossRef]

53. Kim, K.J.; Lee, J.H.; Lee, S.H. Magneto-optical investigation of spinel ferrite $\mathrm{CuFe}_{2} \mathrm{O}_{4}$ : Observation of Jahn-Teller effect in Cu${ }^{2+}$ ion. J. Magn. Magn. Mater. 2004, 279, 173-177. [CrossRef]

54. Kantürk Figen, A.; Taşçi, K.; Coşkuner Filiz, B. Synergetic effect of sodium borohydride addition in ammonia borane hydrolysis reaction mechanism and kinetics. Kinet. Catal. 2018, 59, 128-135. [CrossRef]

55. Estrella, M.; Barrio, L.; Zhou, G.; Wang, X.; Wang, Q.; Wen, W.; Hanson, J.C.; Frenkel, A.I.; Rodriguez, J.A. In situ characterization of $\mathrm{CuFe}_{2} \mathrm{O}_{4}$ and $\mathrm{Cu} / \mathrm{Fe}_{3} \mathrm{O}_{4}$ water-gas shift catalysts. J. Phys. Chem. C 2009, 113, 14411-14417. [CrossRef]

56. Kang, K.S.; Kim, C.H.; Cho, W.C.; Bae, K.K.; Woo, S.W.; Park, C.S. Reduction characteristics of $\mathrm{CuFe}_{2} \mathrm{O}_{4}$ and $\mathrm{Fe}_{3} \mathrm{O}_{4}$ by methane; $\mathrm{CuFe}_{2} \mathrm{O}_{4}$ as an oxidant for two-step thermochemical methane reforming. Int. J. Hydrogen. Energy. 2008, 33, 4560-4568. [CrossRef]

57. Lu, Z.H.; Li, J.; Zhu, A.; Yao, Q.; Huang, W.; Zhou, R.; Zhou, R.; Chen, X. Catalytic hydrolysis of ammonia borane via magnetically recyclable copper iron nanoparticles for chemical hydrogen storage. Int. J. Hydrogen. Energy. 2013, 38, 5330-5337. [CrossRef]

58. Yan, J.M.; Zhang, X.B.; Han, S.; Shioyama, H.; Xu, Q. Magnetically recyclable Fe-Ni alloy catalyzed dehydrogenation of ammonia borane in aqueous solution under ambient atmosphere. J. Power. Sources. 2009, 194, 478-481. [CrossRef]

59. Wang, H.L.; Yan, J.M.; Wang, Z.L.; Jiang, Q. One-step synthesis of Cu@FeNi core-shell nanoparticles: Highly active catalyst for hydrolytic dehydrogenation of ammonia borane. Int. J. Hydrogen. Energy. 2012, 37, 10229-10235. [CrossRef]

60. Qiu, F.; Dai, Y.; Li, L.; Xu, C.; Huang, Y.; Chen, C.; Wang, Y.; Jiao, L.; Yuan, H. Synthesis of Cu@FeCo core-shell nanoparticles for the catalytic hydrolysis of ammonia borane. Int. J. Hydrogen. Energy. 2014, 39, 436-441. [CrossRef]

61. Du, J.; Chen, J.; Xia, H.; Zhao, Y.; Wang, F.; Liu, H.; Zhou, W.; Wang, B. Commercially available CuO catalyzed hydrogenation of nitroarenes using ammonia borane as a hydrogen source. Chem. Cat. Chem. 2020, 12, 2426-2430. [CrossRef]

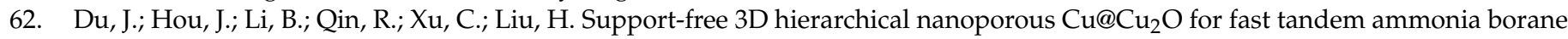
dehydrogenation and nitroarenes hydrogenation under mild conditions. J. Alloys. Compd. 2020, 815, 152372. [CrossRef]

63. Zhou, Y.H.; Yang, Q.; Chen, Y.Z.; Jiang, H.L. Low-cost CuNi@MIL-101 as an excellent catalyst toward cascade reaction: Integration of ammonia borane dehydrogenation with nitroarene hydrogenation. Chem. Commun. 2017, 53, 12361-12364. [CrossRef] [PubMed] 